\title{
BioMedicine
}

Volume 10 | Issue 1

Article 1

2020

\section{Methods of effective low-level laser therapy in the treatment of patients with bronchial asthma}

Follow this and additional works at: https://www.biomedicinej.com/biomedicine

Part of the Life Sciences Commons, and the Medical Sciences Commons (c) (i)

This work is licensed under a Creative Commons Attribution 4.0 License.

\section{Recommended Citation}

Moskvin, Sergey Vladimirovich and Khadartsev, Aleksandr A. (2020) "Methods of effective low-level laser therapy in the treatment of patients with bronchial asthma," BioMedicine: Vol. 10 : Iss. 1 , Article 1.

DOI: $10.37796 / 2211-8039.1000$

This Review Articles is brought to you for free and open access by BioMedicine. It has been accepted for inclusion in BioMedicine by an authorized editor of BioMedicine. 


\title{
Methods of effective low-level laser therapy in the treatment of patients with bronchial asthma (literature review)
}

\author{
Sergey Vladimirovich Moskvin ${ }^{a}{ }^{\text {, }}$, Aleksandr Agubechirovich Khadartsev ${ }^{\mathrm{b}}$ \\ ${ }^{a}$ O.K. Skobelkin State Scientific Center of Laser Medicine under the Federal Medical Biological Agency, Moscow, 121165, Russia \\ ${ }^{\mathrm{b}}$ Medical Institute, Tula State University, Tula, 300028, Russia
}

\section{Abstract}

Bronchial asthma is an autoimmune disease, one of the most common and practically non-treatable by standard methods. At present, the used drugs only maintain a state of temporary remission, simultaneously having a negative effect on various organs and structures and causing side effects.

At the same time, the experts have ignored more than 50 years of successful experience of low-level laser therapy, the results of hundreds of studies proving the effectiveness of the method in treating patients with all forms of bronchial asthma. It is proved that therapeutic and periodic (2-4 per year) courses of low-level laser therapy can significantly decrease the frequency and severity of attacks, reduce or cancel the reception of medicines, as well as negative consequences.

In this brief review, only some part of studies is given as an example; pediatrics issues are almost not discussed. However, the review clearly demonstrates that various methods of laser illumination (specific techniques are given) make it possible to influence almost all the known pathogenesis of the disease, and low-level laser therapy is a truly effective method of treatment.

We note that there are very few publications published on the topic outside of Russia. Russian scientists, as always, are ahead of world science and low-level laser therapy practice.

Keywords: bronchial asthma, low-level laser therapy

B ronchial asthma (BA) is one of the most common diseases of the respiratory system in children and adults. The life-long progression, the high rate of aggravation and the often serious condition at the height of an asthma attack, the limited occupational aptitude and other characteristics increase the social significance of the disease. According to the latest epidemiological studies, more than 339 million people in the world suffer from BA [1]; $7.5 \%$ of the population in the USA is afflicted with it, of which 1.8 million people are hospitalized annually [2]. In Russia, according to epidemiological studies, asthma affects about 7 million people $(5-7 \%$ of adults and
$10-15 \%$ of children) [3]. Many patients have pronounced hormone dependence and/or various hormone-related disorders. Reduced levels of cortisol, testosterone, DHEA-s and estrogen in patients with asthma below the normal range are prognostic criteria for the deterioration of their quality of life $[4,5]$.

Regardless of the severity, BA is a chronic inflammatory disease of the respiratory passages (RPs), occurring with the participation of mast cells, eosinophils and T-lymphocytes, the release of a large number of inflammatory mediators (Fig. 1). Inflammation of the RPs causes their hyperreactivity, bronchial obstruction, and respiratory symptoms. With hyperactivity RPs narrow too easily and/

Received 12 July 2019; accepted 11 September 2019

Available online 28 March 2020

* Corresponding author at: O.K. Skobelkin State Scientific Centre of Laser Medicine under the Federal Medical Biological Agency, Studencheskaya str., 40 , Moscow, 121165, Russia.

E-mail address: 7652612@mail.ru (S.V. Moskvin). 


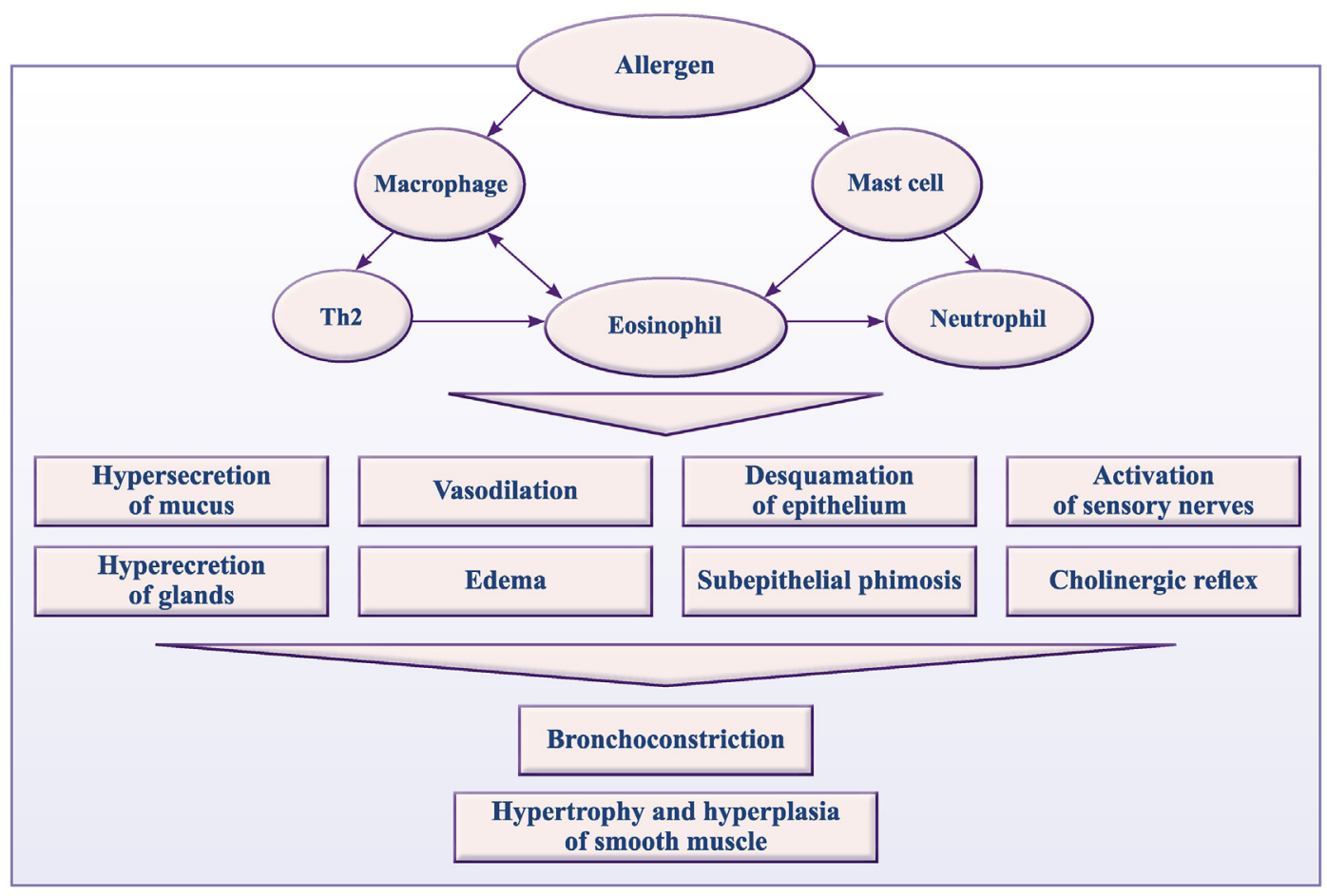

Fig. 1. Inflammation plays the central role in BA pathogenesis.

or strongly in response to the influence of provoking factors. Bronchial obstruction is caused by the following mechanisms: acute bronchospasm, edema of the bronchial wall, obstruction by mucus and remodeling of the bronchial wall. Recurrent exacerbations of asthma are based on inflammation of the bronchi, their remodeling and impaired neurogenic control. An exacerbation of BA is associated with increased inflammation of the RPs and can be induced by a respiratory infection, exposure to allergens, or occupational sensitizing factors. Atopy, the production of excess IgE in response to exposure to exogenous allergens, is an important factor predisposing to the development of BA [3].

According to most experts, for successful treatment of patients with asthma, it is sufficient to properly divide patients according to the disease severity and adjust drug dosages and prescribed regimens for $\beta 2$-agonists and systemic or inhaled glucocorticosteroids (GCS) that have remained for decades [2]. However, there has only been an increase in the number of patients throughout the world, and so far not a single patient has really been cured, i.e., no asthma attacks have been cured permanently. The task is only to provide emergency care [3]. The situation is complicated by the side effects that all drugs have. Even the use of inhaled corticosteroids comes with side effects, especially when consuming high dosages. The resulting systemic absorption often leads to a blockade of the hypothalamic-pituitary-adrenal system and the development of complications such as glaucoma, cataracts, osteoporosis and various skin lesions [6-11].

The development of intoxication and hypoxia, which impede the normal functioning of the immune system, is of great importance in BA pathogenesis. The effect of endotoxins on neutrophils is determined by the severity of all bronchopulmonary diseases, including bronchial asthma. The greatest changes concern molecules of average weight, circulating immune complexes (CIC), lipid peroxidation (LPO) and the toxicity index [12,13]. The increased content of endotoxins in the blood of asthma patients leads to a violation of the albuminbinding capacity and increased intoxication, as evidenced by a sharp increase in the albumin toxicity index [12]. The involvement of histamine and serotonin in BA pathogenesis is generally recognized [14]. The asthma exacerbation phase is characterized by increased histamine and serotonin levels in the blood and plasma, which is accompanied by the development of an intense allergic reaction, reduced phagocytic ability (both in phagocytic number and phagocytic index) and an increased number of NBTpositive neutrophils [12]. 
A ramified chain of events plays a significant role in the pathogenesis of asthma, depending on the functioning of almost all cellular elements of peripheral blood. The number of normal discocytes decreases; the abnormal shapes of erythrocytes with high cholesterol content on the membrane predominate; their deformability decreases, and their aggregation ability increases $[15,16]$. The percentage of abnormal shapes of erythrocytes (echinocytes, teardrop-shaped and target cells, ovalocytes and spherocytes) grows against the background of a decrease in the number of discocytes and an increase in the total number of immature reticulocytes, resulting in the impaired oxygen transport function of the blood and increased hypoxia [17].

According to our data, the main links of the mechanism of therapeutic action in comprehensive low-level laser therapy (LLLT) include the reduction of side effects in the form of local or systemic reactions, the improvement in the indicators of external respiratory function (ERF) and central hemodynamics, positive immune changes, the improvement in adrenal cortex function and the reduction in allergen-specific sensitivity and nonspecific hyperreactivity $[18,19]$.

The therapeutic effect of low-intensity laser illumination (LILI) on BA, according to some authors, begins with the response of immunocompetent cells. The mechanism of formation of the cellular response to laser screening finds its manifestation in the initial phase of the development process, is associated with changes in the activity of enzymes and the structure of plasma membranes, and includes the following steps: molecular membrane rearrangements - reducing cholesterol and fatty acid saturation factor, increasing the proportion of phospholipids and reducing microviscosity; functional modification of membranes - changes in lipid-protein interactions and increased transmembrane potential; and functional modification of cells - an increase in the phagocytic index and neutrophil count $[12,13]$.

As our studies have shown, exposure to LILI in various modes allows for extremely effective increase in the deformability of erythrocyte membranes through their structural rearrangement. At the same time, more than $90 \%$ of erythrocytes with dysfunctional morphology restore their normal discoid shape, which enables reduction of the level of hypoxia [20].

The pathogenetic validity of various methods of LLLT in the comprehensive treatment of patients with asthma was confirmed by numerous studies [21-26]. Some national standards and clinical practice guidelines include almost all known methods: exposure to LILI in the projection of the thymus, adrenal glands, carotid sinus and Zakharyin-Ged zones, laser acupuncture, as well as intravenous laser blood illumination (ILBI) with red (635 nm wavelength) spectrum, and extracorporeal ultraviolet blood illumination (UVBI) $[27,28]$.

Laser therapy should be considered as a multicomponent and pathogenetically substantiated treatment of asthma patients, enabling the reversal of the main symptoms of the disease more quickly with an earlier cancellation or reduction of the drug dosage. These measures contribute to the complete recovery of electrophoregrams, rapid reduction of the elevated sialic acid, seromucoid and ceruloplasmin level and enhanced kinin-kallikrein system activity. After the LLLT course, a more pronounced positive dynamics is observed in the external respiration function (a decrease in the phenomena of bronchial obstruction). In addition to a faster onset and lengthening of remission periods, LLLT allows the body resistance to colds and meteorological factors to increase [26].

The exposure to pulsed IR LILI also has an immunomodulatory effect, along with a positive clinical effect. The latter is manifested by increased metabolic and mitotic activity of lymphocytes, changes in the expression and affinity of Elymphocyte receptors and the serum concentrations of IgM. Neutrophil phagocytosis was significantly enhanced in the immune status of patients after the treatment. From 1989 to 1994 15,526 patients with various immunopathologies, including 2875 adults and 12,651 children, were treated in several medical clinics in Smolensk and Moscow (Russia) [29].

We do not significantly address the topic of treating asthma in children; it deserves a detailed study in a special review, since treatment approaches differ significantly. In this article we only cite several publications from different Russian scientific schools as an example [30-41].

It should be noted that in the English-language publications, and there are very few of them, only laser acupuncture is used and only in the treatment of children [42-49]. In Russia, laser acupuncture is also in active use [50,51], however, most frequently as part of the comprehensive treatment with the adjustment of techniques [52], which is more logical and effective.

A systematic review (search on Cochrane Library, Medline, EMBASE, AMED, CINAHL, CNKI, VIP electronic databases through February 2012), gives 13 randomized placebo-controlled trials (RCTs), the results of which do not prove or disprove the effectiveness of laser acupuncture for the treatment 
of bronchial asthma in children (the data are very contradictory) [53]. However, this is not surprising, since none of the publications describe the use of optimal parameters of laser illumination for laser acupuncture: $635 \mathrm{~nm}$ wavelength, power of 2-3 $\mathrm{mW}$, exposure for 20-40 s per one corporal point, and the maximum permissible values are exceeded manifold, both in terms of laser power and exposure time.

Experimental English-language publications are also few in numbers [54-59], but they are extremely important for understanding the mechanisms of the biological action of LILI.

There are hundreds of times more studies and publications of Russian scholars that not only prove the highest efficiency of laser therapy, but also substantiate the optimal parameters of laser illumination techniques, the principles of drawing up optimal therapeutic schemes, based on many factors. There is nothing similar elsewhere in the world.

Many experts believe that ILBI is the most universal and effective method of laser therapy for asthma patients. The main advantage of ILBI is a significant reduction in the amount of medications taken and a decrease in the number of asthma attacks after treatment [60-62], which is closely related to the severity of the disease and the applied option of the LLLT technique [63].

Table 1 presents the treatment outcomes for three groups of patients after 10 daily laser therapy procedures for such daily average indicators (what fold decrease was shown), as the frequency of asthma attacks and the daily dose of $\beta 2$-agonists. With regard to the GCS, the data is only qualitative: "significant" dose reduction and the ability to make a "soft" transition from systemic to inhaled medications $[63 ; 64]$.

Group 1. Patients with mild and moderate-severe atopic BA and allergic rhinitis were exposed to continuous LILI $(633 \mathrm{~nm}$ wavelength, power of $6 \mathrm{~mW}$ ) endonasally for $5 \mathrm{~min}$ per each nasal passage.

Table 1. Dynamics of reducing the frequency of asthma attacks (AA) and the need for $\beta 2$-agonists in patients with asthma depending on the severity of the disease and laser therapy techniques [67].

\begin{tabular}{|c|c|c|c|c|c|c|}
\hline \multirow{2}{*}{$\begin{array}{l}\text { Methods of } \\
\text { treatment/ } \\
\text { indicators }\end{array}$} & \multicolumn{2}{|c|}{ Light } & \multicolumn{2}{|c|}{$\underline{\text { Medium }}$} & \multicolumn{2}{|c|}{$\underline{\text { Strong }}$} \\
\hline & AA & $\beta 2$-agonists & AA & $\beta 2$-agonists & AA & $\beta 2$-agonists \\
\hline Group 1 & 4,2 & 2,3 & 2,5 & 2,5 & - & - \\
\hline Group 2 & 3,6 & 3,5 & 4,2 & 1,7 & 1,5 & 2,5 \\
\hline Group 3 & - & - & 2,0 & 1,4 & 2,5 & 2,9 \\
\hline
\end{tabular}

Group 2. Patients with mild, moderate-severe and severe atopic and mixed BA were exposed percutaneously to pulsed IR LILI (890 $\mathrm{nm}$ wavelength, power of $5 \mathrm{~W}$, pulse repetition frequency of $150-3000 \mathrm{~Hz}$ ): in the thoracic area, in the areas of projection of the adrenal glands (the lumbar area at the level of $\mathrm{Th}_{12}-\mathrm{L}_{2}$ ), of the thymus (the sternum area at the level of the second rib attachment) and the vascular bundle (the left supraclavicular area).

Group 3. Patients with moderate-severe and severe mixed and atopic BA were exposed to ILBI-635 (635 $\mathrm{nm}$ wavelength, power of $3 \mathrm{~mW}, 45 \mathrm{~min}$ exposure time).

Patients demonstrated positive dynamics in the course of the disease: the number of nocturnal asthma and dyspnea symptoms was reduced, the non-productive cough disappeared, and lung auscultation was normalized. The clinical efficacy of LLLT was confirmed by the ERF studies, and the sputum leukocyte and eosinophil counts also decreased in the patients [64].

Comparative evaluation of the clinical efficacy of LLLT in the comprehensive treatment of asthma patients indicates the need for a differentiated use of various methods depending on the form and severity of the disease [63]. In our opinion, it is always better to apply combined and combinative techniques.

Laser blood illumination (LBI) and most often its intravenous option (ILBI) is the most common method of laser therapy, which is used to treat BA patients. The first successful intravenous laser blood illumination with continuous LILI of the red spectrum (633 $\mathrm{nm}$ wavelength, ILBI-635) was performed in patients with bronchial asthma in the early 1980s, that is, immediately after the technique had appeared $[65,66]$.

ILBI-635 is most effective in patients with the atopic variant of bronchial asthma, who show no effect from specific hyposensitization therapy. In steroid-dependent patients, ILBI makes it possible to reduce the dose of glucocorticosteroids or to discontinue them at all, increasing sensitivity to other medications. Laser therapy can be carried out in any phase of the disease and as the prophylactic treatment in BA patients who have sensitization to plant pollen (prior to the pollination period). LLLT has an immunomodulatory effect, adjusts the ratio between the oxidant and antioxidant systems, and normalizes the indicators of the respiratory function. The application of ILBI in the comprehensive treatment of BA patients can reduce the number of days of disability and lengthen remission periods by 2.4 times [66]. 
A hyperviscosity syndrome has been reported to occur in BA patients: increased whole blood viscosity at low shear rates, reduced deformability and suspension stability of erythrocytes, their increased ability to hyperaggregate, echinocytosis, the tendency of platelets to slow and weakly reversible aggregation [61]. Since the possibilities of exposure to LILI that normalize blood rheology are well known, S.A. Borzenkov (2000) [61] used ILBI-635 (wavelength $633 \mathrm{~nm}$, power of $2 \mathrm{~mW}, 30 \mathrm{~min}$ exposure time, 10 procedures per a treatment course daily) in the comprehensive treatment of BA patients with positive clinical outcomes that correlated with normalized rheological parameters. The minimum shear stress decreased by $14 \%$, whole blood viscosity reduced (at a shear rate of $1 \mathrm{cP}$ - by $17 \%$, at a shear rate of $9 \mathrm{cP}$ - by $12 \%$, at a shear rate of $25 \mathrm{cP}$ by $21 \%$, at a shear rate of $100 \mathrm{cP}-$ by $22 \%$, and at a shear rate of $256 \mathrm{cP}$ - by $28 \%$ ), single-unit RBC count decreased by $47 \%$, and the echinocyte count reduced by $49 \%$ as well, the RBC deformability increased by $1.2 \%$ and the non-aggregated $\mathrm{RBC}$ count increased by $1.18 \%$.

But at the same time, no effect on platelet aggregating properties was found in BA patients. The application of ILBI in the comprehensive treatment of asthma patients also enables decrease in the drug dosage taken by more than $20 \%$ and reduction of hospital lengths of patients' stay on average by 2.91 days.

The use of ILBI-635 $(633 \mathrm{~nm}$ wavelength, $1-1.5 \mathrm{~mW}, 30 \mathrm{~min}$ exposure time, 10 procedures per a treatment course daily) to treat asthma enables to obtain a more pronounced normalizing effect on bronchial patency, reduce the degree of hypoxemia, contribute to the improvement of the clinical picture of the disease [17].

The synergistic effect of medication and laser therapies on central hemodynamics, microcirculation and blood rheological properties makes it possible to cancel prolonged $\beta 2$-agonists and reduce doses of systemic GCS [67], when prescribing ILBI sessions, which is essential to compensate for the negative effect of glucocorticoid therapy on the morphofunctional state of endobronchial microhemocirculation [68].

ILBI-635 is known to have pronounced immunomodulatory properties associated with the effect of illumination on the lymphoid elements of peripheral blood, which is also indicated for BA patients. In addition, the content of physiologically active substances, including glucocorticoid hormones, is also changed in these patients. The level of total 11oxycorticosteroids (11-OCS) increases from (2-20).
$10^{-5} \mathrm{~g} / 1$ to $(10-50) \cdot 10^{-5} \mathrm{~g} / 1$ in the patients' serum after five procedures of ILBI [69].

In patients with asthma in the acute phase, the balance between LPO and the antioxidant system (AOS) is disturbed, and the antioxidant activity of blood significantly decreases [12]. There is an oxidative stress, which is expressed in significant (exceeding the average in healthy people by 12 times) hyperproduction of free-radical metabolites against the background of $20 \%$ decreased activity of intracellular antioxidant enzymes. The use of inhaled GCS with the standard treatment of BA patients leads to the positive dynamics of clinical and functional parameters, but does not have an appreciable impact on LPO and AOC parameters. In standard therapy using systemic GCS patients show a significant decrease in LPO (by 33\% of baseline values) with simultaneous inhibition of AOC parameters (by $12 \%$ of baseline values). When combining systemic and inhaled GCS, LPO parameters decrease less (by $25 \%$ ), but the extent of inhibition of AOS parameters is greater (a decrease by $16 \%$ ) [70]. Therefore, it is required to additionally adjust LPO and AOS parameters against the background of GCS use in BA patients, at the same time the ability of ILBI to normalize LPO processes is well enough confirmed [71].

The most significant AOS disorders are observed in hormone-dependent BA patients, but these patients show the best treatment outcomes after a course of ILBI-635 (633 nm wavelength, power of $3 \mathrm{~mW}, 20 \mathrm{~min}$ exposure time, $8-10$ procedures per a treatment course daily). These results are correlated with a significant increase in the activity of antioxidant enzymes and a decrease in LPO intensity in RBC. Against the background of ILBI, a decrease in the average dosage of systemic GCS and a more relaxed transition to inhaled drugs have been observed. Patients who received ILBI against the background of traditional therapy as opposed to patients, who were traditionally treated, experienced faster clinical dynamics of the disease: decrease in the number of asthma attacks, replacement of full-scale attacks of asphyxiation with symptoms of dynamic bronchial obstruction, and decrease in cough intensity. Against the background of low-level laser therapy, there was a significant reduction in the need for bronchodilators and GCS doses. The average bed-occupancy rate was $10.7 \%$ less in such patients than in those who received only traditional therapy. The most pronounced improvement in respiratory function was observed in the group of patients with newly developed asthma [72-74]. 
Research by V.I. Korzhov et al. (1989) [75] showed that ILBI-635 in the comprehensive treatment of BA patients enables to achieve remission in $92.1 \%$ of cases and the phase of unstable remission in $7.9 \%$ of cases (in the control group 73.8 and $26.2 \%$, respectively). At the same time, in patients of the main group (ILBI), the disappearance or decrease in the number of asthma attacks occurred in 5-6 days, while in the control group this result was achieved in $8-10$ days. A reliable decrease (by $15.8 \%$ ) was established in the concentration of molecules with average weight as compared to the initial level, and after treatment this parameter practically becomes equal to that in healthy donors $-238 \pm 10.5$ units. Analysis of the dynamics of accumulation of LPO products revealed an increase in their level in the studied patients; however, as a result of the treatment provided, the degree of normalization of both intermediate and final compounds is very significant. Thus, the content of lipid hydroperoxides decreased by $12.8 \%$ from the initial level, the decrease in the concentration of malondialdehyde (MDA) was even more significant - by $34 \%$.

An increase in the conjugated diene concentrations is registered in all patients with moderate-severe asthma during exacerbation of the disease. These changes directly depend on asthma duration $[73,74,76]$. Comprehensive treatment, including ILBI procedures (633 nm wavelength, power of $2-3 \mathrm{~mW}$, $20 \mathrm{~min}$ exposure time, $8-10$ procedures per a treatment course daily), to a greater extent contributes to reducing the intensity of LPO processes as compared to traditional treatment.

The content of antioxidants in erythrocytes and plasma increases in the exacerbation phase in BA patients with short duration of the disease. In patients with the disease duration of more than 10 years against the background of an exacerbation, a decrease is registered in the concentration of antioxidants in the studied media, respectively. The application of ILBI-635 demonstrates a more pronounced tendency to normalize the studied parameters, i.e. this method is a powerful corrective tool for affecting patients' AOS as well [77-79]. Other authors also confirmed the best efficacy of laser therapy with disease duration of more than 10 years and a more severe course than with newly diagnosed BA [80].

All BA patients have changes in the cytokine profile, cellular and humoral immunity, the nature of which depends on the severity of the disease and on the available allergic reactions. With an increase in the severity of the disease, serum immunoglobulin (IgA) levels increase, while IgG and $\operatorname{IgE}$ decrease, which is accompanied by an increase in the number of granulocytes with the phenotype $\mathrm{CD} 45+\mathrm{CD} 66 \mathrm{~b}+\mathrm{CD} 11 \mathrm{~b}+$ and enhanced phagocytic activity of neutrophils: the phagocytic number increase by 3-16 times, and the phagocytic index grows by 3.5-4 times as compared to healthy donors. Peripheral blood mononuclear cells isolated in the exacerbation phase of bronchial asthma are characterized by increased production of IL-4 (spontaneous production is 6.3 times as high, induced one is 4.8 times as high), IL-6 (spontaneous production is 2.4 times as high, induced one is 4.3 times as high) and IL-17 (spontaneous production increases by $23 \%$, induced one - by $19 \%$ ). The level of spontaneous production of IL- 8 is reduced by $7 \%$, while that of the induced one is increased by $7.5 \%$. In this connection, recently, special importance has been attached to immunomodulatory therapy [81]. Low-level laser therapy has also fairly powerful capabilities in this component of the physiological regulation.

It has been shown that in patients with an infectious-dependent form of BA ILBI-635 contributes to the normalization of the number of E-rosetting cells, a decrease in the content of theophylline-resistant subpopulation of T-cells enhanced upon admission and an increase in the number of theophyllinesensitive subpopulation of T-cells, which leads to the normalization of theophylline-resistant-totheophylline-sensitive T-cell ratio: $\mathrm{E}_{\text {th-r }}-\mathrm{ROS} / \mathrm{E}_{\text {th-s }}-$ ROS [82]. After a course of ILBI-635, dyspnea is reduced, the external respiratory function improves, a more rapid recovery of alveolar blood flow is observed, a distinct stimulating effect on the cell level parameters of phagocytic activity of neutrophils is reported $[83,84]$.

It is most effective to administer ILBI-635 $(633 \mathrm{~nm}$ wavelength, 1-2 $\mathrm{mW}, 30 \mathrm{~min}$ exposure time, 5-7 procedures per a treatment course daily) for patients with moderate depression of the T-cell immunity. ILBI can be successfully used as monotherapy in BA patients with mild disease and drug polyallergy. The distinct positive dynamics in the T-cell immunity naturally manifests itself in an accelerated and pronounced regression of the clinical implications of the disease [85].

The inclusion of ILBI -635 in the comprehensive therapy of infection-dependent BA increases the effectiveness of treatment: it accelerates the time for remission onset and increases its duration, reduces the frequency of exacerbations and enables to decrease the amount of drug therapy. Under the influence of ILBI, the inflammatory process subsides, which is reflected in ERF improvement (VC increases by $39.9 \%$, FVC - by $27.9 \%$, FEV1 - by $41.6 \%$, MEF50 - by $42.0 \%$, MEF75 - by $47.4 \%$, MEF 25 
- by $58.3 \%$ ), with marked fall in peripheral blood eosinophils and positive general clinical dynamics [86].

L.V. Vasilieva (1999) [87] showed the following effects of ILBI-635 in bronchial asthma:

- stimulation of $\beta$-adrenergic receptors;

- increase in the functional activity of lymphocytes and leukocytes, and phagocytic activity of neutrophils and monocytes;

- normalization of immunoglobulin levels and CIC;

- restoration of the aggregative state of blood.

The use of intravenous laser blood illumination in the comprehensive treatment of BA patients reliably improves bronchial patency compared with the results of conventional therapy. ILBI-635 has a corrective effect on the hemostatic system, mainly optimizes Hageman-kallikrein-dependent fibrinolysis, which determines an additional mechanism of its action. In addition, ILBI has anti-aggregation properties, reduces the coagulation potential, increases the antioxidant activity of the blood and decreases pre-beta cholesterol and beta cholesterol levels [88]. RBC morphometry and electrophoretic mobility measurement in BA patients after ILBI procedures show that the proportion of discocytes in the blood recovers almost to the norm [89].

Many experts are sure that the combination of plasmapheresis (PA) or enterosorption + laser blood illumination is one of the most effective options of therapy, including for BA patients [28,60,62,90-93].

Plasmapheresis combined with ILBI-635 allows for significant (by 60\%) improvement of performance in patients with the most severe clinical course of asthma and concomitant autoimmune thyroiditis. Comprehensive therapy not only contributes to obtaining stable long-term remission, control over the BA symptoms, but also significantly reduces the antibody titer to the thyroid microsomal fraction [90].

Against the background of comprehensive therapy applying PA, UVBI and ILBI, in most cases, it is possible to achieve clinical remission in BA patients with a pronounced reduction in the amount of drug therapy, up to the discontinuation of hormonal drugs. It was shown that the therapeutic effect of the extracorporeal and laser therapy techniques is implemented by enhancing the therapeutic efficacy of sympathomimetic agents [94], and increasing the immunosorption and insulin-binding capacity of erythrocyte membranes [94,95].

Combining drug therapy of BA patients with PA and ILBI-635 it is possible to accelerate the onset of the disease remission through more rapid reverse development of asthma attacks, which results in the considerable increase in exercise tolerance and ERF normalization. With a significant reduction in the volume of drugs, the periods of remission are simultaneously extended. Combined treatment can prevent the development of complications by reducing the total doses of hormonal drugs or their discontinuation. LLLT contributes to more rapid stabilization of the bronchial receptor apparatus, in particular of $\beta$-adrenoreceptors, increasing their sensitivity to sympathomimetics and glucocorticoid drugs. Combination of ILBI and PA to treat patients with various forms of asthma corrects immune disorders and phagocytosis dysfunction, which is one of the main pathogenetic mechanisms causing a pronounced clinical effect and improving the course of the disease [60].

These outcomes are confirmed by other authors. Against the background of PA and ILBI-635, cough disappears in earlier periods and lung auscultation is normalized, while the dose of oral GCS is reduced, doubling the remission duration. After the course of LLLT, respiratory indicators that characterize the bronchial patency are normalized by the end of the 3rd week of treatment, providing rapid functional activation of the oxygen-dependent bactericidal system of blood neutrophils (NBT-test), which is associated with an additional increase in the T-lymphocyte suppressor potential, normalized immunoregulatory index and increased phagocytic activity of neutrophils [96-98].

According to A.S. Kuno (1994) [99], it is necessary to include immunomodulators in the treatment regimen in addition to PA and UVBI, which enable to prolong remission by stabilizing humoral immunity.

Along with ILBI, laser acupuncture is quite actively used to treat BA patients; more often, as we have noted above, as part of the comprehensive therapy with other methods of low-level laser therapy applied $[52,93,100,101]$.

It was shown that the optimal time for local exposure in treating patients with allergic BA by pulsed IR LILI $(890 \mathrm{~nm}$ wavelength, 5-7 W, $700-1600 \mathrm{~Hz}$ ) is $60 \mathrm{~s}$ (paravertebrally), $300 \mathrm{~s}-$ supraclavicular region, by illuminating APs for $30 \mathrm{~s}$ (stimulation) and 60-90 s (suppression). The following acupuncture points were used: V10 (Tianzhu), V11 (Dazhu), V13 (Feishu), V12 (Fengmen), V15 (Xinshu), V17 (Geshu), CV22 (Tiantu), VC21 (Xuanji), VC20 (Huagai), VC17 (Shanchung).), VC16 (Zhongting), VC15 (Jiuwei), RP6 (Sanyinjiao), E14 (Kufang), E15 (Wuyi), E36 (Zusanli), GI4 (Hegu), P7 (Lieque), P11 (Shaoshang). Auricular points: AAP55 (Shen Men point, having general 
strengthening effect), AAP31 (Ping Chuan, Asthma point, relieving symptoms of asthma, calming panting, etc.), AAP13 (Adrenal Control point). Against the background of combined laser therapy, a positive ERF dynamics is observed, rhinocytogram indices are normalized, there is reduction in general and local eosinophilia), cutaneous and, especially, local sensitivity to specific allergens. The positive clinical effect of the therapy is accompanied by the immune normalization: T-lymphocyte and T-helper cell counts significantly increase, the level of serum immunoglobulins (IgA and $\operatorname{IgG}$ ) raises, and the percentage of degranulated mast cells decreases [103].

Considerably worse results were obtained by M.A. Borodina (1999) [104], either because of a different acupuncture prescription, or because of the multifactorial effect on APs (simultaneous exposure to LILI, magnet and heat). An alternative prescription is given by foreign authors: P5 (Chize), P7 (Lieque), P9 (Taiyuan), GI4 (Hegu), V13 (Feishu), V23 (Shenshu), E36 (Zusanli), RP6 (Sanyinjiao), VG14 (Dazhui), VC17 (Shanchung). However, as is often the case, they use completely unacceptable LILI parameters [42], and perhaps for this reason their results are not the best ones.

I.E Yesaulenko et al. (2009) [105] recommended a simplified prescription to treat BA patients with concomitant chronic rhinosinusitis: GI4 (Hegu), P7 (Lieque), GI20 (Yingxiang) and P5 (Chize), ZP15 (Jiabi), VG23 (Shangxing), AAP22 symmetrically on alternate days, 10 procedures per a treatment course daily.

Laser acupuncture can significantly improve the results of outpatient treatment and rehabilitation of patients with light and moderate-severe asthma statistically significantly earlier than with conventional drug therapy.

Patients with severe BA demonstrate the best result with comprehensive therapy. The clinical course improves, bronchial sensitivity to sympathomimetics is restored, the need for $\beta 2$-agonists, inhaled and systemic GCS is reduced, Short-Term Disability periods decrease by $5-7$ days, remission duration is prolonged to 3 years, there is reduction in frequency of hospitalization by 1.3 times, emergency call incidence by $23 \%$, and disability retirement rate to $12 \%$.

The restoration of impaired histochematic barrier and systemic changes in the synthesis and utilization of biogenic amines by the blood cells that stimulate the production of mature heparin, which binds inflammatory mediators - histamine and serotonin, as well as an excess of catecholamines is the basic mechanism of therapeutic action of LILI.
Heparin has anti-inflammatory value and removes the blockade of $\beta 2$-adrenergic receptors, and catecholamines produce bronchodilation, by binding to $\beta 2$-adrenergic receptors [51].

Summing up some intermediate result of the brief review, we have systematized the results of various studies (Table 2), which clearly demonstrate the normalizing effect of laser illumination on virtually all known pathogenetic mechanisms of asthma development, therefore, there is no doubt that laser therapy can and should be used as the basic method of therapy. However, there is still a very important issue about the optimization of laser therapy parameters; the answer to this question helps gain knowledge of the mechanism of therapeutic action of LILI and some rules. Sometimes it is hindered by incorrect description of materials and research methods [16], which raises doubts about the reliability of their results, but there are so many publications (Table 2 gives only a small part of them as an example) that it is easy to draw conclusions about the optimal techniques.

Laser blood illumination, as we said above, is the most commonly used method for treating BA. While the issue with the optimal power for the "classical" ILBI-635 technique (633 $\mathrm{nm}$ wavelength) can be considered solved (it should be $1-3 \mathrm{~mW}$ ), the issue with the exposure time is more complicated. Previously, laser illumination was performed by many authors for $30 \mathrm{~min}$ or even more [17,61,85], although it has long been unequivocally proven that the exposure time for this mode of ILBI should not exceed 15-20 min. Moreover, this conclusion was made not only for bronchial asthma [76], but also for other pathological processes and diseases [20].

It is known that in order to get the best treatment outcome it is necessary to combine various methods of LLLT for topical and systemic action [20], but this is especially important if the patient has several diseases.

Comparative evaluation of the clinical efficacy of laser therapy in the comprehensive treatment of BA patients against the background of hormonal disorders confirmed that precisely the combined methods are most optimal when using laser illumination techniques of both primarily topical and systemic action on the entire body as a whole [110; 122; 123]. Combining ILBI-635 and external LILI for patients with various hormonal disorders characteristic of asthma improves the quality of patients' life [5]. Long-term treatment of BA patients using systemic GCS increases the risk of developing osteoporosis. Low-level laser therapy (ILBI-635) is an effective means of preventing complications and helps normalize testosterone and estradiol levels 


\begin{tabular}{|c|c|c|c|}
\hline Form of BA; clinical outcome & Indicator & LLLT technique (number of daily procedures) & Referenc \\
\hline \multicolumn{4}{|l|}{ Antioxidant System } \\
\hline $\begin{array}{l}\text { ABA, children; reduction of bronchospasm attacks and } \\
\text { dyspnea, up to the complete disappearance }\end{array}$ & $\begin{array}{l}\text { Activation of AOS, reduction of the level of primary and final } \\
\text { LPO products }\end{array}$ & ILBI-635 (3-5) & [106] \\
\hline $\begin{array}{l}\text { MBA; earlier normalization of the main clinical and } \\
\text { laboratory signs, reduction of the dose of GCS }\end{array}$ & Reduction of MDA, lipid hydroperoxides, increase in SOD & $\begin{array}{l}\text { ILBI- } 635 \text {, external pulsed IR LILI: paravertebrally } \\
\mathrm{Th}_{3}-\mathrm{Th}_{5} \text {, at the II and III intercostal space, } \\
\text { symmetrically, projection of the adrenal } \\
\text { glands (14) }\end{array}$ & [87] \\
\hline $\begin{array}{l}\text { IABA; a significant decrease in the amount of medications } \\
\text { taken and a reduction of the number of asthma attacks }\end{array}$ & $\begin{array}{l}\text { Normalization of the work of AOS for all studied parameters } \\
\text { (DC, MDA, Schiff bases, SOD, catalase, glutathione peroxidase, } \\
\text { glutathione reductase) }\end{array}$ & Enterosorption and ILBI -635 (10) & [62] \\
\hline $\begin{array}{l}\text { ABA, IABA, MBA; reduction of doses of hormonal drugs } \\
\text { and cancellation, reduction of the days of disability, } \\
\text { lengthening the terms of remission } 2.4 \text { times }\end{array}$ & $\begin{array}{l}\text { Decrease in the content of LPO products (DC, MDA), increase in } \\
\text { enzyme activity (SOD, catalase), stabilization of cell membranes }\end{array}$ & ILBI-635 (5-12) & [66] \\
\hline In vivo, mice & $\begin{array}{l}\text { Reduction of ROS content, decrease in activity of NO-synthase in } \\
\text { bronchoalveolar lavage fluid, increase in catalase activity, SOD, } \\
\text { glutathione peroxidase, NADPH oxidase, and Nrf2 transcription } \\
\text { factor }\end{array}$ & $660 \mathrm{~nm}, 30 \mathrm{~mW}, 5 \mathrm{~min}(1)$ & [55] \\
\hline In vitro, U937 cells & $\begin{array}{l}\text { Suppression of glucocorticoid resistance induced by oxidative } \\
\text { stress, inhibition of TNF- } \alpha \text { and IL- } 8 \text { secretion through an increase } \\
\text { in cAMP and inhibition of the PI } 3 \text { K signaling pathway }\end{array}$ & $660 \mathrm{~nm}, 17,85 \mathrm{~mW} / \mathrm{cm}^{2}, 60 \mathrm{~s}(1)$ & [58] \\
\hline \multicolumn{4}{|l|}{ Immune system } \\
\hline Not indicated & Decrease in eosinophil count & Laser acupuncture (10-20) & [107] \\
\hline $\begin{array}{l}\text { ABA, children; reduction of bronchospasm attacks and } \\
\text { dyspnea, up to the complete disappearance }\end{array}$ & Normalization of the ratio of T-and B-lymphocytes & ILBI-635 (3-5) & [106] \\
\hline $\begin{array}{l}\text { IABA; decrease in skin and, especially, local sensitivity to } \\
\text { specific allergens }\end{array}$ & $\begin{array}{l}\text { Reduction of general and local eosinophilia is accompanied by } \\
\text { normalization of immunity: the content of T-lymphocytes, T- } \\
\text { helpers increases, the level of serum immunoglobulins A and G } \\
\text { increases, the percentage of degranulated mast cells decreases }\end{array}$ & Laser acupuncture $(10-15)$ & [103] \\
\hline $\mathrm{ABA}$ & Normalization of $\operatorname{IgA}$, IgG and $\operatorname{Ig} M$ levels & LBI, laser acupuncture, in the projection (10) & [18] \\
\hline $\begin{array}{l}\text { MBA; a significant decrease in the amount of medications } \\
\text { taken and a reduction of the number of asthma attacks } \\
\text { after LLLT course }\end{array}$ & $\begin{array}{l}\text { Normalization } \operatorname{Ig} A, \operatorname{IgG}, \operatorname{Ig} M, \operatorname{IgE} \text { levels, activation of } \\
\text { phagocytosis }\end{array}$ & PA and ILBI-635 (4-7) & [60] \\
\hline $\begin{array}{l}\mathrm{ABA}, \mathrm{IABA} \text { with concomitant autoimmune thyroiditis; } \\
\text { increase in the duration of remission }\end{array}$ & $\begin{array}{l}\text { Reduction of antibody titer to the microsomal fraction of the } \\
\text { thyroid gland }\end{array}$ & PA and ILBI-635 (3-5) & [90] \\
\hline In vitro & Changes in the morphofunctional state of lymphocyte membranes & $633 \mathrm{~nm}(1)$ & [108] \\
\hline ABA, MBA; decrease in the frequency of attacks & Decrease in eosinophil count & Endonasal, topical, ILBI (10) & {$[63,64]$} \\
\hline ABA, children & Reduction of $I g E$ level & Laser acupuncture (10) & [52] \\
\hline MBA and $\mathrm{COB}$; rapid regression of clinical symptoms & Activation of T-cellular component of immune system & ILBI-635 (5-7) & [85] \\
\hline $\begin{array}{l}\text { MBA, children; clinical symptoms are reduced 3-6 days } \\
\text { faster }\end{array}$ & $\begin{array}{l}\text { Reduction of IgE, VEGF, IL8, IL4 levels, CD4 + lymphocytes, } \\
\text { increase in CD8 + lymphocytes }\end{array}$ & Laser acupuncture (10) & [32] \\
\hline IABA & Normalization of the ratio of Eth-r-ROS/Eth-s-ROS & ILBI-635 (5-8 on alternate days) & [82] \\
\hline IABA; remission occurs one week faster, its duration & Activation of neutrophils of peripheral blood & PA and ILBI-635 $(8-10)$ & [96] \\
\hline
\end{tabular}

ABA children; reduction of bronchospasm attacks and dyspnea, up to the complete disappearance

MBA; earlier normalization of the main clinical and

ABA; a significant decrease in the amount of medications

BA, IABA, MBA, reduction of doses of hormonal drug and cancellation, reduction of the days of disability, lengthening the terms of remission 2.4 times

In vivo, mice

increases; the severity of the disease decreases and the

frequency of exacerbations is reduced 2 times; the dose

of oral corticosteroids is reduced
Activation of AOS, reduction of the level of primary and final LPO products

Reduction of MDA, lipid hydroperoxides, increase in SOD

ymmetrically, projection of the adrenal

glands (14)

ILBI-635 (5-12)

] 


Form of BA; clinical outcome
Not indicated
ABA, children; absence of severe asthma attacks and the
frequency of attacks of moderate and mild severity are
$1.8-2.5$ times less
ABA, adults and children

ABA, adults and children

ABA, children; decrease in the number of asthma attacks 4 -6 times, reduction of the severity of the disease ABA, HBA

\section{Not indicated}

ABA, IABA, MBA; normalization of sensitivity and reactivity of the bronchi

Illumination of the blood of patients with MBA in vitro

Not indicated, children; the number of exacerbations

decreased 3 times, the need for antibiotics decreased 3.7

$$
\text { times }
$$

In vivo, mice

In vivo, mice

In vivo, rats

\section{Muscle tone}

In vivo, rats

In vivo, rats

\section{Neuroendocrine system}

$\mathrm{ABA}$

MBA; a significant decrease in the amount of medications taken and a reduction of the number of asthma attacks after LLLT course

$$
\text { MBA }
$$

Aspirin BA; 2 times lower doses of GCS and 2-2.5 times of Increase in ACTH and cortisol levels in the blood $\beta 2$-agonists

Not indicated; reduction of GCS doses

Indicator

Reduction of IgG, CIC levels, increase in phagocytosis and

normalization of the immunoregulatory index of the T-system of immunity

Normalization of levels of immunoglobulins of the main classes and reduction of the initially high level of IgE, normalization of phagocytosis and levels of proinflammatory cytokines in blood serum

Increase in metabolic and mitotic activity of lymphocytes, neutrophil phagocytosis, changes in the expression and affinity of E-receptors of lymphocytes, a decrease in IgM concentration in blood serum

Normalization of IgA, IgG, IgM, IgE, IL-1 $\beta$ and TNF- $\alpha$ levels

Decrease in the number of eosinophils, normalization of IgA, IgG and IgM levels

Normalization of T-cell immunity

Normalization of T-lymphocyte differentiation, increase in Tsuppressor activity, decrease in $\operatorname{IgE}$ production

Increase in phagocytic index and neutrophil count

Normalization of almost all investigated parameters of the

immune stat

Reduction of $\operatorname{IgE}$ level

Decrease in the number of eosinophils and bronchia

hyperactivity through the expression of the RhoA gene,

reduction of allergic lung inflammation through the expression of the STAT6 gene

Decrease in the number of eosinophils, IL-4 and IgE levels, increase in the production of IFN- $\gamma$, the ratio of T-helpers $T h_{1} / T h_{2}$ is normalized

Relaxation of the inflammatory smooth muscle of the trachea, TNF- $\alpha$ inhibition, cAMP accumulation

Decrease in cholinergic hyperactivity, elimination of bronchia smooth muscle spasm, reduction of the expression of mRNA TNF- $\alpha$

Initial low blood cortisol increases

The sensitivity of $\beta$-adrenoreceptors to sympathomimetics an glucocorticoid drugs is increased

Increase in testosterone levels in men and estradiol in women

LLLT technique (number of daily procedures)

PA and ILBI-635 (3-4)

External pulsed IR LILI (10)

External pulsed IR LILI (5-8)

Externally on several areas by continuous

LILI of red spectrum $(633 \mathrm{~nm})$ and pulsed IR $(890 \mathrm{~nm})$ LILI $(7-10)$

$660 \mathrm{~nm}, 30 \mathrm{~mW}, 5 \mathrm{~min}(1)$

$660 \mathrm{~nm}, 30 \mathrm{~mW}, 5 \mathrm{~min}(1)$

$810 \mathrm{~nm}, 20 \mathrm{~mW} / \mathrm{cm}^{2}, 20 \mathrm{~min}(21)$

$650 \mathrm{~nm}, 31,25 \mathrm{~mW} / \mathrm{cm}^{2}, 42$ and $300 \mathrm{~s}(1)$

$655 \mathrm{~nm}, 31,25 \mathrm{~mW} / \mathrm{cm}^{2}, 42 \mathrm{~s}$ and $5 \mathrm{~min}(1)$

LBI, laser acupuncture, in the projection (10) PA and ILBI-635 (4-7)

Pulsed IR LILI in the projection of the adrenal glands and NLBI (10)

Hemosorption and ILBI-635 (8)

Normalization of aldosterone levels, increase in steroid hormones levels in the blood
Pulsed IR in the projection of the upper respiratory tract $(10-15)$ 
Not indicated

\section{Not indicated}

Vascular system, hemorheology

ABA, children; reduction of bronchospasm attacks and dyspnea, up to the complete disappearance Not indicated

Not indicated; a significant decrease in the amount of medications taken and a reduction of the number of asthma attacks after LLLT course

ABA

MBA, children

$\mathrm{MBA}+$ hypertensive disease

IABA; remission occurs one week faster, its duration

increases; the severity of the disease decreases and the frequency of exacerbations is reduced 2 times; the dose of oral GCS is reduced

Not indicated, combination with MS

IABA; improvement of bronchial patency

Not indicated

IABA

HBA, IABA; reduction in the amount of drug therapy up to cancellation of hormonal drugs

ABA, IABA; broncholytic effect, cancellation of prolonged $\beta 2$-agonists and reduction of doses of systemic GCS

IABA; the main symptoms of the disease are stopped more quickly with an earlier cancellation or reduction of the dose of drugs

Respiratory function (normalization of indicators)

IABA

ABA

MBA; earlier normalization of the main clinical and

laboratory signs, reduction of the dose of glucocorticoids

taken
Initially reduced levels of cortisol and catecholamines in the blood increase, initially increased levels of histamine and serotonin are reduced

Increase in mineralcorticoid function of the adrenal cortex, normalization of the ionic composition of blood (potassium, sodium)

Increase in levels of 11-oxycorticosteroids (11-OCS) in the blood

Improvement of the structure of erythrocyte membranes

Lengthening the blood clotting time, reduction of fibrinogen concentration and increase in fibrinolytic activity of blood

Improvement of the rheological properties of blood, increase in the deformability of erythrocyte membranes, decrease in the

content of echinocyte

Changes of indicators of central hemodynamics

Normalization of erythrocyte and platelet parameters, restoration

of endothelium-dependent characteristics (endothelin-1 and

circulating endotheliocytes)

Normalization of blood lipid spectrum

mprovement of central and peripheral hemodynamics

ILBI-635 (5)

ILBI-635 (3-5)

Laser acupuncture (10-20)

ILBI-635 (10)

LBI, laser acupuncture, in the projection (10)

Pulsed IR LILI in the projection of lungs (10)

ILBI-635 (-)

PA and ILBI-635 $(8-10)$

Normalization of blood lipid spectrum

ILBI-635 (8-10)

ILBI-635 (5)

Hageman-kallikrein-dependent fibrinolysis is optimized, antiaggregation effect appears, coagulation potential decreases, blood antioxidant activity increases, pre-beta cholesterol and beta cholesterol levels decrease

Normalization of blood lipid spectrum

Restoration of the form of erythrocytes, an increase in the proportion of discocytes in the blood

Increase in immunosorption and insulin binding ability of erythrocyte membranes

Favorable effect on central hemodynamics, microcirculation and rheological properties of blood

LLLT contributes to a more complete recovery of foregrams, a rapid decrease in elevated levels of sialic acids, seromucoids, ceruloplasmin, and the activity of the kinin-kallikrein system

$\mathrm{VC}, \mathrm{FVC}$

VC, FVC, $\mathrm{MEF}_{25-75}, \mathrm{FEV}_{1}, \mathrm{FEV}_{1} / \mathrm{FVC}$

C, FVC, $\mathrm{MEF}_{25-75}, \mathrm{FEV}_{1}, \mathrm{FEV}_{1} / \mathrm{FVC}$
Laser acupuncture (10-20)

ILBI-635 (10)

PA, UVBI and ILBI-635 (10)

Laser acupuncture, continuous LILI (633 nm) on reflex zones (10-19 depending on the severity)

Laser acupuncture (10-15)

LBI, laser acupuncture, in the projection (10)

ILBI-635, external pulsed IR LILI: paravertebrally

Th3-Th5, at the II and III intercostal space

symmetrically, the projection of the adrenal glands (14)

(continued on next page) 


Form of BA; clinical outcome

MBA

ABA, children

ABA; elimination of bronchospasm

MBA, children

ABA, MBA; decrease in the frequency of attacks

MBA and COB; rapid regression of clinical symptoms

MBA, children; clinical symptoms are reduced 3-6 days faster

ABA, children; absence of severe asthma attacks and the frequency of attacks of moderate and mild severity are 1.8-2.5 times less

$\mathrm{BA}$ and hypertensive disease

MBA

ABA, IABA, MBA

ABA, IABA, MBA; elimination of bronchial obstruction syndrome

ABA, HBA; the need for $\beta 2$-agonists, inhalation and systemic GCS decreases, the period of temporary disability decreases by $5-7$ days, the duration of remission increases up to 3 years

ABA, children; absence of severe asthma attacks and reduction of the frequency of attacks of moderate and mild severity

IABA

MBA; improvement of bronchial patency of large, medium and small bronchi due to a pronounced anti-

inflammatory, bronchodilator, anti-edematous,

antioxidant action

MBA with rhinosinusitis

Not indicated, children; improvement according to GINA

criteria in $91.7 \%$ of patients, reduction of doses of medications

Not indicated, children

Not indicated, children

Not indicated, children

Not indicated, children

Not indicated, children; improvement of the quality of life

Indicator

FVC, $\mathrm{FEV}_{1}, \mathrm{FEV}_{1} / \mathrm{FVC}$

PEF, FEV

VC, FVC, $\mathrm{FEV}_{1}, \mathrm{FEV}_{1} / \mathrm{FVC}$, PEF, etc.

FVC, PEF

VC, FVC, $\mathrm{MEF}_{25-75}, \mathrm{FEV}_{1}, \mathrm{FEV}_{1} / \mathrm{FVC}$, PEF

VC, FVC, $\mathrm{MEF}_{25-75}, \mathrm{FEV}_{1}, \mathrm{FEV}_{1} / \mathrm{FVC}$

VC, FVC, $\mathrm{MEF}_{25-75}, \mathrm{FEV}_{1}, \mathrm{FEV}_{1} / \mathrm{FVC}$

VC, FVC, $\mathrm{MEF}_{25-75}, \mathrm{FEV}_{1}, \mathrm{FEV}_{1} / \mathrm{FVC}$, PEF

$\mathrm{MEF}_{75}, \mathrm{FEV}_{1}, \mathrm{PEF}_{25-75}$, normalization of blood pressure

$\mathrm{FEV}_{1}, \mathrm{PEF}$, reduction of endogenous intoxication

VC, FVC, $\mathrm{MEF}_{25-75}, \mathrm{FEV}_{1}, \mathrm{FEV}_{1} / \mathrm{FVC}$

VC, FVC, $\mathrm{FEV}_{1}, \mathrm{FEV}_{1} / \mathrm{FVC}, \mathrm{PEF}$

VC, FVC, $\mathrm{FEV}_{1}, \mathrm{MEF}_{50,75}$

LLLT technique (number of daily procedures)

Reference

Pulsed IR LILI in the projection of the adrenal

glands and NLBI (10)

Laser acupuncture (10)

Laser acupuncture (10-20)

Endonasal, topical, ILBI (10)

ILBI-635 (5-7)

Laser acupuncture (10)

External pulsed IR LILI (10)

External, NLBI (10)

NLBI, laser acupuncture (12-14)

NLBI, ILBI-635 (8)

ILBI-635 (5-12)

Laser acupuncture $(10-15)$

118

[80]

[66]

VC, FVC, $\mathrm{MEF}_{25-75}, \mathrm{FEV}_{1}, \mathrm{FEV}_{1} / \mathrm{FVC}, \mathrm{PEF}$

External pulsed IR LILI (10)

VC, FVC, $\mathrm{MEF}_{25-75}, \mathrm{FEV}_{1}, \mathrm{FEV}_{1} / \mathrm{FVC}, \mathrm{PEF}$

LBI-635 (5

NLBI (10)

[86]

VC, FVC, $\mathrm{MEF}_{25-75}, \mathrm{FEV}_{1}, \mathrm{FEV}_{1} / \mathrm{FVC}, \mathrm{PEF}$

Pulsed IR LILI endonasally

Laser acupuncture (10)

VC, $\mathrm{FEV}_{1}, \mathrm{FEV}_{1} / \mathrm{FVC}, \mathrm{PEF}$

$\mathrm{FEV}_{1}, \mathrm{MEF}_{25}$

$\mathrm{PEF}$

$\mathrm{VC}, \mathrm{FVC}, \mathrm{MEF}_{25-75}, \mathrm{FEV}_{1}$

PEF, FEV 1

Laser acupuncture (10)

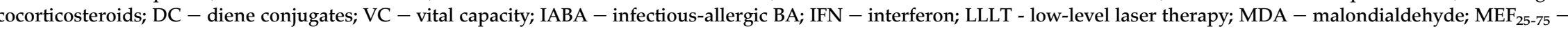
maximal expiratory flow at $25 \%-75 \%$; MS - metabolic syndrome; NLBI- non-invasive (percutaneous) laser blood illumination; $\mathrm{FEV}_{1}-\mathrm{forced}_{\mathrm{m}}$ expiratory volume in $1 \mathrm{~s}$; $\mathrm{FEV}_{1} / \mathrm{FVC}-$ the Tiffeneau index; PA - plasmapheresis; LPO - lipid peroxidation; PEF - peak expiratory flow rate; MBA - mixed BA; SOD - superoxide dismutase; FVC - forced vital capacity; cAMP - cyclic adenosine monophosphate; CIC - circulating immune complexes; GINA - Global Initiative for Asthma; IL - interleukin; NF- $k B$ - nuclear factor-kappa B; NO nitrogen oxide; $P I 3 K$ - phosphoinositide 3-kinase; $T N F-\alpha$ - tumor necrosis factor-alpha; VEGF - vascular endothelial growth factor. 
[124]. Combining ILBI-635 and external LILI is most effective for osteoporosis prevention in patients taking GCS [44].

The availability of BA determines the peculiarities of hypertension progression, since a sharp rise in blood pressure often occurs at the time of a suffocation attack or an increase in bronchial obstruction, leading to negative consequences. Laser therapy in this case acts as a non-specific therapeutic factor, providing a pronounced double effect, promoting the improvement of the bronchial patency of the large, medium and small bronchi due to a pronounced anti-inflammatory, bronchodilatory, antiedematous, antioxidant action, simultaneously normalizing blood pressure and preventing its sharp jumps $[117,119,120]$.

The efficacy of combined LLLT for patients with asthma and stage 1 hypertensive disease is $80 \%$, and for patients with asthma and stage 2 hypertensive disease is $70 \%$, respectively. It is recommended to expose consistently the projection of the vasomotor center of the brain - the region of the posterior cranial fossa ( $1 \mathrm{~min}, 800-1500 \mathrm{~Hz}$ frequency), the projection of kidneys (for $5 \mathrm{~min}$ per each, $80-1500 \mathrm{~Hz}$ frequency), the projection of the lower lung lobes symmetrically ( $2 \mathrm{~min}, 80 \mathrm{~Hz}$ frequency) with pulsed IR LILI (904 $\mathrm{nm}$ wavelength, $100 \mathrm{~ns}$ light pulse duration, 8-10 W) paravertebrally at the $\mathrm{C}_{4}-\mathrm{C}_{6}$ level, at the $\mathrm{Th}_{2}-\mathrm{Th}_{6}$ level (for 1 min per each, $80-150 \mathrm{~Hz}), 10$ procedures per a treatment course daily [117].

A special situation develops in BA patients with hormonal disorders and metabolic syndrome (MS). In case of bronchial disorders accompanied by bronchial obstruction, the leading role in the genesis of the impaired functional status of the adrenal glands is assigned to chronic hypoxia and hypoxemia (as a result of impaired bronchial patency and alveolar hypoventilation), which are the trigger mechanisms of stress. Rapid response activation of the hypothalamic-pituitary-adrenal system causes a standard non-specific reaction in the form of adrenocortical hypertrophy, lymph node atrophy, etc. In the conditions of pathology, the adaptive role of a number of hormones consists primarily in their influence on the development of inflammatory processes. The possibility of correcting the neuroendocrine system work after laser therapy is confirmed by the normalized serum aldosterone levels in such patients [6].

There are common key links in the pathogenesis of BA and MS: energy dependence of these processes, increased consumption of plastic material with involvement of the immune system in pathological reactions, activation of cytokine mechanisms, intense work of the endocrine system with active release of hormones and neurotransmitters into the blood. With this in mind, it can be assumed that a proper correction of MS contributes to the development of positive dynamics for the bronchial asthma progression. Laser therapy methods allow obtaining good treatment outcomes and are an effective means of preventing the development of complications [113-115]. The developed method of combined therapy for BA patients can increase the treatment efficacy and shorten the treatment duration, prevent side effects, correct hormone levels and reduce the dose of drugs used. Against the background of drug therapy, patients are exposed to NLBI and pulsed IR LILI in the projection of the adrenal glands. In this case, the NLBI is performed for $15 \mathrm{~min}$ at a wavelength of $635 \mathrm{~nm}$. Before the 1st and 5th procedures of exposure to the pulsed IR LILI, the levels of cortisol and estradiol in women and testosterone in men are determined. At cortisol levels below $230 \mathrm{nmol} / 1$ and testosterone levels below $500 \mathrm{ng} / \mathrm{dl}$ in men and estradiol levels below $30 \mathrm{pg} / \mathrm{ml}$ in non-menopausal women and below $15 \mathrm{pg} / \mathrm{ml}$ in menopausal women, a pulse repetition frequency of $150 \mathrm{~Hz}$ is used. At the cortisol levels ranging from 230 to $750 \mathrm{nmol} / \mathrm{l}$ and estradiol levels ranging from $30 \mathrm{pg} / \mathrm{ml}$ to $160 \mathrm{pg} / \mathrm{ml}$ in women and testosterone ranging from 260 to $1593 \mathrm{ng} / \mathrm{dl}$ in men, a pulse repetition frequency of $80 \mathrm{~Hz}$ is used. The total time of the procedure is no more than $18 \mathrm{~min}$. The treatment course consists of 10-12 daily procedures [125].

External illumination by pulsed IR LILI is carried out in BA patients either in the projection of the upper respiratory tract to stimulate $\beta$-adrenergic receptors, eliminate inflammation and bronchospasm, or in the projection of the adrenal cortex to stimulate the release of steroid hormones $[26,109,110,114]$. Most often, both variants are used with the aim of simultaneously affecting several mechanisms of the disease pathogenesis.

The possibility of using reflex zones in treating patients with allergic asthma for stimulation of blood circulation and trophism is noted. In this case laser illumination is performed paravertebrally in the $\mathrm{C}_{7}-\mathrm{Th}_{6}$ area in addition to exposing the projection of the inflammatory infiltrate and the adrenal cortex. When using this technique, persistent remission (no recurrence within 2-3 years) was observed in $14 \%$ of patients (with mild progression of the disease), who simultaneously stopped taking GCS. Relative remission, characterized by the absence of full-scale asphyxiation attacks during 1.5-2 years and occasional difficulties in breathing, occurred in $65 \%$ of patients [26]. 
We have shown the need to control the hormone content in the process of laser therapy of BA patients. A method of exposure was proposed, consisting in illuminating two paravertebral and intercostal regions and two Krenig fields by pulsed IR LILI (890 nm wavelength, $8-10 \mathrm{~W} / \mathrm{cm}^{2}$ power density, 1500-3000 $\mathrm{Hz}$ frequency, $5 \mathrm{~min}$ exposure time, 10 procedures per a treatment course daily). This technique is characterized by the use of additional modulation in the well-known "BIO" mode (synchronization of changes in the LILI power with patient's pulse and respiration frequency). In addition, after the 1st and 3rd LLLT procedures, the content of 11-oxicorticosteroids (11-OCS) is determined; in case of a decrease in their content further treatment continues. In the majority of patients $(80 \%)$ with a good and satisfactory effect of LLLT, there was a significant decrease in the level of 11-OCS in the blood plasma and daily urine after the 1st procedure, and this trend continued until the end of the treatment. In patients with an unsatisfactory treatment outcome, the level of 11-ACS either did not change or tended to increase. The mode of illumination (power, frequency) was modified in a number of patients based on the change in the level of 11-OCS after the first procedure. In some cases, the dynamics of 11-OCS in the absence of a pronounced clinical effect suggested the indirect effect of LILI on metabolic processes in the lungs, which was confirmed later on by significantly better curability of patients when using drug therapy [126].

When treating BA patients with metabolic syndrome, Kryuchkova et al. (2011) [127] recommended combining ILBI with external exposure to green light. Although in our opinion, this is hardly more effective than pulsed infrared LILI, even if we consider the situation only in terms of the depth of penetration, not to mention the special "healing properties" of coherence [128]. Light in the green region of the spectrum, regardless of the monochromaticity degree, is almost completely absorbed already in the upper layers of the skin, penetrating no more than a few millimeters, and therefore, it cannot directly affect the bronchi [20]. Although the issues of implementing the reflex mechanism and psychotherapeutic effects may well be discussed.

Endobronchial technique, which was used by some experts $[129,130]$, did not find practical application due to the complexity of implementation with the worst treatment outcomes, which are achieved by using other methods of laser illumination.

Summing up the literature review, knowing the disorders that underlie the pathogenesis of the disease (Fig. 1), as well as the biomodulating mechanisms of the LLLT, we have drawn a scheme (Fig. 2) that clearly illustrates the basic mechanisms underlying the treatment of patients with bronchial asthma.

It seems promising to use low-intensity illumination of the extremely high-frequency range and laser light (EHF-laser therapy) [131], some progress has already been achieved in this direction [132,133], but the optimization of exposure parameters is clearly required.

Proceeding from the above data and an understanding of the methodology as a whole, we present laser therapy techniques with optimal parameters that are recommended for the treatment of patients with various forms of bronchial asthma, once again emphasizing the need for combination and variation.

ILBI-635 Technique: Matrix and Lasmik laser therapeutic devices, KL-ILBI-635-2 laser emitting head (635 $\mathrm{nm}$ wavelength, light guide output power of 1.5-2.5 $\mathrm{mW}, 15-20 \mathrm{~min}$ exposure time), 5-10 procedures per a treatment course daily [83,87]. Based on the well-known fact that the LLLT efficacy is observed with a disease duration exceeding 10 years and a more severe course than with newly diagnosed BA, it is recommended to reduce the exposure time for this category of patients down to 3-5 min for ILBI-635 [80].

It is also required to reduce the exposure time down to at least 7-10 $\mathrm{min}$ in all children (5-7 procedures per a treatment course daily) [106]. Although, in our opinion, in pediatrics, it is preferable to use a non-invasive option of the laser blood illumination technique - in the projection of the supraclavicular region on the left (the technique parameters depend on age).

For the last 8-10 years such "classic" version of ILBI has been actively supplanted by a more effective combined technique, which allows both influencing the immune system and activating metabolism. It is highly recommended to combine laser blood illumination with plasmapheresis.

ILBI-635 + LUVBI $^{\circledR}$ Technique: Matrix and Lasmik laser therapeutic devices, KL-ILBI-635-2 laser emitting head (red spectrum, $635 \mathrm{~nm}$ wavelength, light guide output power of 1.5-2 $\mathrm{mW}, 10-20 \mathrm{~min}$ exposure time) and KL-ILBI-365-2 laser emitting head 365-405 nm wavelength, light guide output power of $1.5-2 \mathrm{~mW}, 3-5 \mathrm{~min}$ exposure time). It is recommended to perform $10-12$ procedures per a treatment course daily with mode alternation in a day [20].

ILBI-525 + LUVBI $^{\circledR}$ Technique: Matrix and Lasmik laser therapeutic devices, KL-ILBI-525-2 laser emitting head (green spectrum, $525 \mathrm{~nm}$ wavelength, light guide output power of $1.5-2 \mathrm{~mW}, 7-10 \mathrm{~min}$ exposure time) and KL-ILBI-365-2 laser emitting 


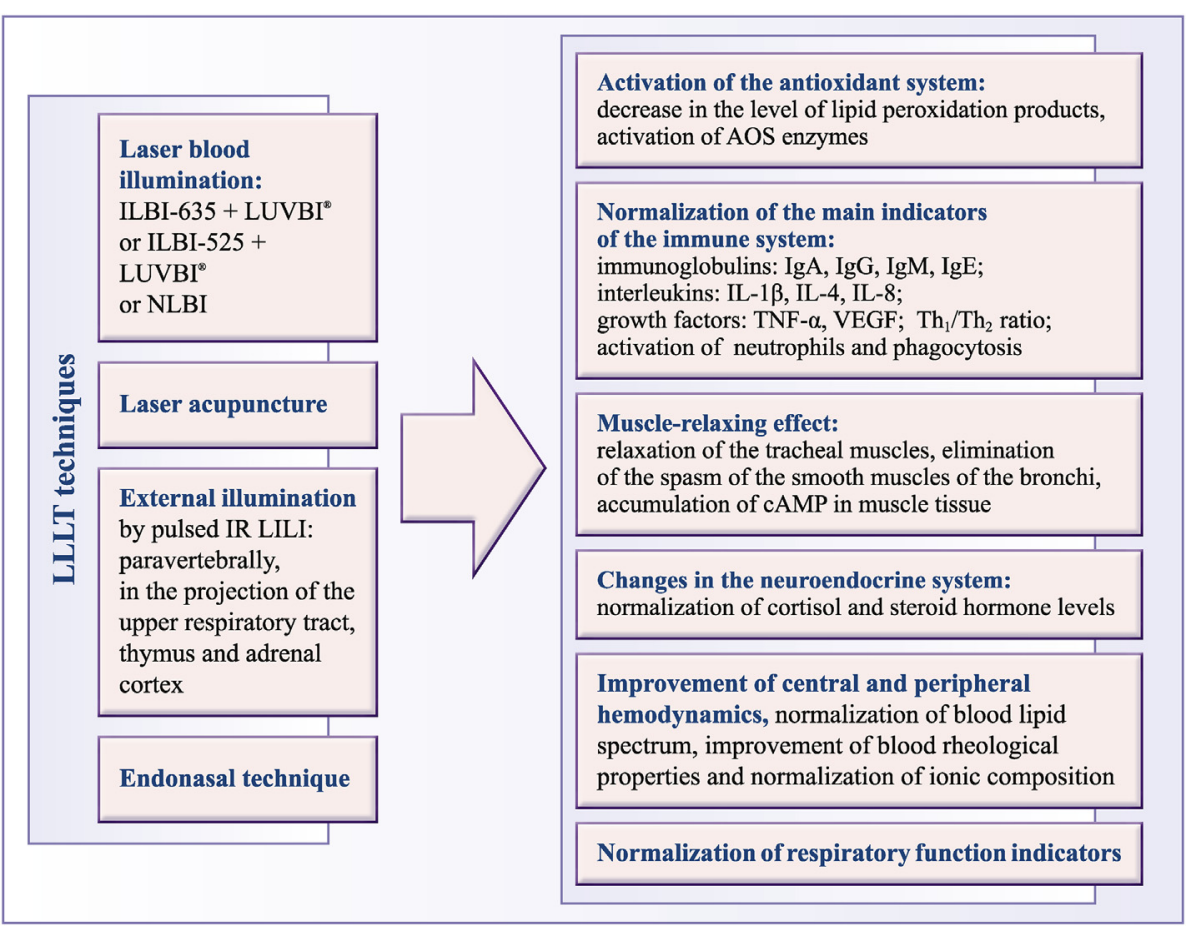

Fig. 2. Low-level laser therapy mechanisms in the treatment of BA patients.

head 365-405 $\mathrm{nm}$ wavelength, light guide output power of $1.5-2 \mathrm{~mW}, 3-5 \mathrm{~min}$ exposure time). It is recommended to perform 10-12 procedures per a treatment course daily with mode alternation in a day [20]. The most advanced version of ILBI, which has proven its effectiveness in many diseases; however, it is necessary to conduct appropriate clinical studies and test the applicability in bronchial asthma.

According to S.V. Papkov (2002) [80], regardless of the LLLT technique used, in the overwhelming majority of cases, the course treatment of BA patients should be limited to 8 procedures daily for $10-15 \mathrm{~min}$, since longer exposure has a stressful effect, leading to worsening of some autonomic parameters of the body. From this viewpoint, ILBI-525 + LUVBI $^{\circledR}$ technique is also preferable to ILBI-635.

Non-invasive laser blood illumination (NLBI): The technique is not applied on the same day as ILBI. Wavelength of $635 \mathrm{~nm}$, pulsed mode, ML-635-40 matrix laser emitting head (Matrix or Lasmik device, eight 4-5 W laser diodes), power of $50-80 \mathrm{~W}$, power density of $4-5 \mathrm{~W} / \mathrm{cm}^{2}$, frequency of $80 \mathrm{~Hz}$ (variation is not allowed).

Laser acupuncture: Wavelength of $635 \mathrm{~nm}$, continuous or modulated operation mode, and the output power at a special acupuncture nozzle is 2-3 $\mathrm{mW}$, to be exposed for 20-40 s on one corporal point, the prescription is selected individually or on the recommendation of specialists.

In the projection of the internal organs Wavelength of $904 \mathrm{~nm}$, pulsed mode, ML-904-80 matrix laser emitting head (Matrix or Lasmik device, eight $10 \mathrm{~W}$ laser diodes), power of $50-80 \mathrm{~W}$, power density of $8-10 \mathrm{~W} / \mathrm{cm}^{2}$, frequency of $80 \mathrm{~Hz}$ (variation is allowed).

Localization (projection) and exposure time:

- upper respiratory tract - 2 or $5 \mathrm{~min}, 1-2$ areas;

- thymus - $1 \mathrm{~min}$;

- adrenal cortex - 2 or 5 min per area symmetrically.

Paravertebrally: Wavelength of $904 \mathrm{~nm}$, pulsed mode, LO-904-20 matrix laser emitting head with a mirror expender (Matrix or Lasmik device, one laser diode), power of 15-20 W, power density of $10-15 \mathrm{~W} / \mathrm{cm}^{2}$, frequency of $80 \mathrm{~Hz}$ (variation is not allowed) at the level of $\mathrm{C}_{4}-\mathrm{C}_{6}$ and $\mathrm{Th}_{2}-\mathrm{Th}_{6}$ symmetrically, 1 min per each region.

Endonasal technique: The application of the technique is associated with the execution of certain mandatory rules. Continuous LILI of the red spectrum (635 $\mathrm{nm}$ wavelength, light guide output power of $3-5 \mathrm{~mW}$ ) through the light guide or directly via the laser emitting head to expose for 2 min per one nasal passage. The efficacy and validity of the 
technique is beyond doubt [64; 134]; however, it is necessary to carefully consider its purpose, to control the technique parameters, especially the exposure time.

In case of bronchial asthma with concomitant chronic rhinosinusitis, another technique is used, although the nasal area is exposed. Firstly, only pulsed IR LILI (890-904 nm, 5-10 W, $80 \mathrm{~Hz}$ ) should be used, secondly, there is other localization: projections of maxillary sinuses and/or frontal sinuses and/or ethmoidal sinuses (depending on the localization of the inflammatory process according to $x$ ray or computed tomography data) on both sides, for 2 min each [121].

Most often, 10-15 daily procedures are recommended per a treatment course. Although there are other options, both upwards and downwards, we agree precisely with this approach. Fewer procedures will not allow obtaining a stable clinical effect, and more does not make sense according to the logic of the known patterns of chronobiology and chronomedicine.

The issue of alternating different techniques is also very important. In our opinion, if guided by the well-known rule of limiting the total procedure time to 20-25 $\mathrm{min}$, then on one day 2-3-4 different options of laser illumination may and should be performed. The opinion of some experts that it is optimal to combine ILBI-635 with the exposure to pulsed IR LILI in the projection of the trachea region (supradorsal) and paravertebral every other day, 10-12 procedures per a treatment course daily [122], is most likely related to the wrong exposure time selected for ILBI.

Thus, low level laser therapy for BA patients with proper prescription and appropriate procedures, results in sustained remission throughout the patient's entire life. Moreover, drugs are not excluded from the treatment regimen, but are considered as part of the auxiliary treatment to provide emergency care in case of unforeseen and/or provoked exacerbation. Courses of prophylactic laser therapy are recommended: $3-5$ procedures daily or every other day, at least $3-4$ times a year $[26,36,60,82,85,86]$. It is preferable to use two techniques, most often ILBI and topical exposure. A course of prophylactic treatment is additionally prescribed for patients with allergic BA before the onset of seasonal exacerbation.

\section{Conflicts of interest statement}

The authors disclose no conflicts of interest.

\section{References}

[1] The global asthma report 2018. Auckland, New Zealand: Global Asthma Network; 2018.

[2] McCracken JL, Veeranki SP, Ameredes BT, Calhoun WJ. Diagnosis and management of asthma in adults: a review. J Am Med Assoc 2017;318(3):279-90. https://doi.org/ 10.1001/jama.2017.8372.

[3] Avdeev SN, Nenasheva NM, Zhudenkov KV Petrakovskaya VA, Izyumova GV. Prevalence, morbidity, phenotypes and other characteristics of severe bronchial asthma in Russian Federation. Russ Pulmonol 2018;28(3): 341-58 [Russian] doi: 18093/0869-0189-2018-28-3-341-358.

[4] Vasilyeva LV, Izmalkov DV. Assessing low intensive laser radiation clinical effect on the disease course and the state of bone tissue in treating patients with bronchial asthma combined with endocrinal abnormalities. J N Med Technol 2011;18(2):238-40 [Russian].

[5] Vasilyeva LV, Titova LA. Quality of life of patients with bronchial asthma because of the influence of combined medical and laser therapy. J N Med Technol 2011;18(2): 240-2 [Russian].

[6] Nikitin AV, Titova LA. Clinical efficiency of applying laser therapy for treating patients with bronchial asthma at the background of hormonal disorders. J N Med Technol 2011; 18(2):306-8 [Russian].

[7] Cumming RG, Mitchell P, Leeder SR. Use of inhaled corticosteroids and the risk of cataracts. N Engl J Med 1997; 337(1):8-14. https://doi.org/10.1056/NEJM199707033370102.

[8] Garbe E, LeLorier J, Boivin JF, Suissa S. Inhaled and nasal glucocorticoids and the risks of ocular hypertension or open-angle glaucoma. J Am Med Assoc 1997;277(9):722-7.

[9] Monk B, Cunliffe WJ, Layton AM, Rhodes DJ. Acne induced by inhaled corticosteroids. Clin Exp Dermatol 1993;18(2): 148-50.

[10] Smith MJ, Hodson ME. Effects of long term inhaled high dose beclomethasone dipropionate on adrenal function. Thorax 1983;38(9):676-81. https://doi.org/10.1136/ thx.38.9.676.

[11] Wang JJ, Rochtchina E, Tan AG, Cumming RG, Leeder SR, Mitchell $P$. Use of inhaled and oral corticosteroids and the long-term risk of cataract. Ophthalmology 2009;116(4): 652-7. https://doi.org/10.1016/j.ophtha.2008.12.001.

[12] Novozhilova OS. Biochemical parameters of blood in bronchopulmonary diseases. Abstract of the thesis. Ufa; 2007 [Russian].

[13] Fedotova GG. Morphofunctional study of neutrophils in endotoxicosis. Abstract of the thesis. Saransk; 2007 [Russian].

[14] Lutsenko MT. Morphological analysis of peripheral blood cells in patients with bronchial asthma. Bull Physio-Pathol Respir 2000;7:1-20 [In Russian].

[15] Lavrova OV. Features of hemorheology disorders in patients with bronchial asthma. Abstract of the thesis. Leningrad. 1990 [Russian].

[16] Paleev FN, Ostrovskiy EI, Karandashov VI, Shatokhina SN Sanina NP, Ryzhkova OY, et al. The influence of photohaemotherapy on blood rheology in bronchial asthma. Alm Clin Med 2015;43:58-65. https://doi.org/10.18786/20720505-2015-43-58-65.

[17] Tsybzhitova EB. Morphofunctional characteristics of peripheral component of erythron in patients with chronic nonspecific lung diseases in the dynamics of treatment. Abstract of the thesis. Moscow. 2010 [Russian].

[18] Borisova ON, Khadartsev AA. Diagnosis and non-drug methods of influence in the clinic of internal diseases. Part I. Tula; 2004 [Russian].

[19] Khadartsev AA, Khoruzhaya VA, Danilyak IG. The use of laser irradiation in the treatment of patients with bronchial asthma. Clin Med 1988;6:53-6 [Russian]. 
[20] Moskvin SV, Konchugova TV, Khadartsev AA. The commonest therapeutic methods for laser irradiation of blood. Vopr Kurortol Fizioter Lech Fiz Kult 2017;94(5):10-7. https://doi.org/10.17116/kurort201794510-17 [Russian].

[21] Asiryan EG, Novikov PD. Laser therapy in the treatment and rehabilitation of patients with bronchial asthma. Protect Mother Child 2015;1(25):70-4 [Russian].

[22] Ermukhambetov TK. On some functional indicators of respiration in patients with bronchial asthma during treatment with laser irradiation. In: Proceedings of Resp. conf. "Some issues of biodynamics and bio-energy of the body in health and pathology, biostimulation with laser irradiation." Part 2. Alma-Ata; 1972. p. 137-41 [Russian].

[23] Ermukhambetov TK. Spirographic and some biophysical indicators in patients with bronchial asthma during treatment with monochromatic coherent light. Abstract of the thesis. Alma-Ata; 1980 [Russian].

[24] Kuchin NN, Ermukhambetov TK. Application of low-intensity monochromatic coherent light in the treatment of patients with bronchial asthma and hypertension. On the main directions of scientific research. Alma-Ata; 1986. p. 252-60 [Russian].

[25] Chikisheva IV. Experience of application of laser therapy in bronchial asthma. Abstracts of the All-Union. conf. on applic. of lasers in medicine (Krasnoyarsk, 1983). - Moscow. 1984. p. 123-4 [Russian].

[26] Chikisheva IV. The effectiveness of low-intensity laser irradiation in patients with infectious-allergic form of bronchial asthma. Abstract of the thesis. Kharkov; 1987 [Russian].

[27] Novikov DK, Novikov PD. Clinical immunopathology: a guide. Moscow: Meditsinskaya literatura; 2009 [Russian].

[28] Novikov DK, Novikov PD, Titova ND. Immunocorrection, immunoprophylaxis, immunorehabilitation. Vitebsk: VSMU; 2006 [Russian].

[29] Meshkova RYa. Screening of patients with immune system disorders and providing specialized medical and diagnostic care:. Abstract of the thesis. Moscow. 1996 [Russian].

[30] Glazova TG, Ryvkin AI, Lariushkina RM, Pobedinskaya NS, Tentelova IV, Reshetova TG. Low intensity laser radiation in the rehabilitation in children with bronchial asthma: pathogenetic substantiation and effectiveness. Bull Ivanovo Med Acad 2016;21(1):56-60 [Russian].

[31] Glazova TG, Ryvkin AI, Pobedinskaya NS, Laryushkina RM. Various therapeutic complexes in bronchial asthma in children: efficacy analysis. Bull Ivanovo Med Acad 2013;18(4):56-7 [Russian].

[32] Deryabina EV. Immunomodulating therapy in the complex treatment of uncontrolled bronchial asthma in children. Abstract of the thesis. Samara. 2011 [Russian].

[33] Zhilnikov DV, Tarasova ON, Plaksina GV, VYu Loskutov, YuE Zubova, Vycherova AN, et al. Experience of using lowintensity laser irradiation in the treatment of bronchial asthma that is one of the main environmentally related diseases in children. Alm Clin Med 2002;5:178-85 [Russian].

[34] Illek YY, Muratova NG, Korotkova EI, Polyakova OA. The influence of magnetic infrared laser therapy on clinical parameters and external breathing function of children with bronchial asthma. Vyatskiy meditsinskiy vestnik $2005 ; 3-4$ : 6-8 [Russian].

[35] Illek YY, Zajtseva GA, Muratova NG, Smirnov AV. Clinical and immunomodulating effects of magnetic infrared laser therapy at children with severe atopical bronchial asthma. Vyatskiy meditsinskiy vestnik 2007;2-3:73-6 [Russian].

[36] Korotkova EI. Effectiveness of magnetic infrared laser therapy in children with atopic bronchial asthma. Abstract of the thesis. Perm. 2005 [Russian].

[37] Kusselman AI, Deriabina EV. Magnetic-infrared-laser therapy in uncontrolled bronchial asthma in children. Allergol Immunol Pediatry 2010;1(20):16-23 [Russian].

[38] Muratova NG. Clinical and immunological status and options for its correction with varying severity of atopic asthma in children. Abstract of the thesis. Saint Petersburg 2007 [Russian].

[39] Rostova AV. Drug and non-drug therapy in the prevention of exacerbations in children with bronchial asthma in the prehospital phase. Abstract of the thesis. Saint Petersburg. 2007 [Russian].

[40] Smirnov AV. Clinical efficacy of magnetic infrared laser therapy and its effect on the immune system in children with severe bronchial asthma. Abstract of the thesis. Moscow. 2005 [Russian].

[41] YuE Tserkovnaya. Opportunities to improve the effectiveness of treatment of children with bronchial asthma in a health resort. Abstract of the thesis. Moscow. 2008 [Russian].

[42] Dabbous OA, Soliman MM, Mohamed NH, Elseify MY Elsheikh MS, Alsharkawy AA, et al. Evaluation of the improvement effect of laser acupuncture biostimulation in asthmatic children by exhaled inflammatory biomarker level of nitric oxide. Laser Med Sci 2017;32(1):53-9. https:// doi.org/10.1007/s10103-016-2082-9.

[43] Elseify MY, Mohammed NH, Alsharkawy AA, Elseoudy ME. Laser acupuncture in treatment of childhood bronchial asthma. J Compl Integr Med 2013;10. https:// doi.org/10.1515/jcim-2012-0006.

[44] Gruber W, Eber E, Malle-Scheid D, Pfleger A, Weinhandl E, Dorfer L, et al. Laser acupuncture in children and adolescents with exercise induced asthma. Thorax 2002;57(3): 222-5.

[45] Hirsch D, Leupold W. Placebo-controlled study on the effect of laser acupuncture in childhood asthma. Atemwegs und Lungenkrankheiten 1994;12:701-5 [Article in German].

[46] Milojević M, Kuruc V. Low power laser biostimulation in the treatment of bronchial asthma. Med Pregl 2003; 56(9-10):413-8 [Article in Serbian].

[47] Morton AR, Fazio SM, Miller D. Efficacy of laser-acupuncture in the prevention of exercise-induced asthma. Ann Allergy 1993;70(4). 295-258.

[48] Nedeljković M, Ljustina-Pribić R, Savić K. Innovative approach to laser acupuncture therapy of acute obstruction in asthmatic children. Med Pregl 2008;61(3-4):123-30. https://doi.org/10.2298/MPNS0804123N [Article in Serbian].

[49] Stockert K, Schneider B, Porenta G, Rath R, Nissel H, Eichler I. Laser acupuncture and probiotics in school age children with asthma: a randomized, placebo-controlled pilot study of therapy guided by principles of Traditional Chinese Medicine. Pediatr Allergy Immunol 2007;18(2): 160-6. Erratum in: Pediatr Allergy Immunol. 2007; 18(3): 272.

[50] Ostronosova NS. Low-intensity laser radiation in therapy of bronchial asthma. Vopr Kurortol Fizioter Lech Fiz Kult 2006; 2:8-10 [Russian].

[51] Ostronosova NS. Pathophysiological rationale for laser stimulation of acupuncture points in the treatment of bronchial asthma. Abstract of the thesis. - Moscow. 2006 (1). [Russian].

[52] Danilina TN. The use of laser puncture in the treatment of bronchial asthma. Abstract of the thesis. Samara. 2004 [Russian].

[53] Zhang J, Li X, Xu J, Ernst E. Laser acupuncture for the treatment of asthma in children: a systematic review of randomized controlled trials. J Asthma 2012;49(7). https:// doi.org/10.3109/02770903.2012.691194. 773-737.

[54] Aimbire F, Bjordal JM, Iversen VV, Albertini R, Frigo L, Pacheco MTT, et al. Low level laser therapy partially restores trachea muscle relaxation response in rats with tumor necrosis factor alpha-mediated smooth airway muscle dysfunction. Laser Surg Med 2006;38(8):773-8. https://doi.org/10.1002/1sm.20357.

[55] Costa Carvalho JL, de Brito AA, de Oliveira AP, de Castro Faria Neto HC, Pereira TM, de Carvalho RA, et al. The chemokines secretion and the oxidative stress are targets of low-level laser therapy in allergic lung inflammation. 
J Biophot 2016;9(11-12):1208-21. https://doi.org/10.1002/ jbio.201600061.

[56] Mafra de Lima F, Costa MS, Albertini R, Silva Jr JA, Aimbire F. Low level laser therapy (LLLT): attenuation of cholinergic hyperreactivity, $\beta_{2}$-adrenergic hyporesponsiveness and TNF- $\alpha$ mRNA expression in rat bronchi segments in E. coli lipopolysaccharide-induced airway inflammation by a NF- $\kappa B$ dependent mechanism. Laser Surg Med 2009; 41(1):68-74. https://doi.org/10.1002/lsm.20735.

[57] Silva VR, Marcondes P, Silva M, Villaverde AB, CastroFaria-Neto HC, Vieira RP, et al. Low-level laser therapy inhibits bronchoconstriction, Th2 inflammation and airway remodeling in allergic asthma. Respir Physiol Neurobiol 2014;194:37-48. https://doi.org/10.1016/j.resp.2014.01.008.

[58] Souza NH, Marcondes PT, Albertini R, MesquitaFerrari RA, Fernandes KP, Aimbire F. Low-level laser therapy suppresses the oxidative stress-induced glucocorticoids resistance in U937 cells: relevance to cytokine secretion and histone deacetylase in alveolar macrophages. J Photochem Photobiol, B 2014;130:327-36. https://doi.org/ 10.1016/j.jphotobiol.2013.12.010.

[59] Wang X-Y, Ma W-J, Liu C-S, Li Y-X. Effect of low-level laser therapy on allergic asthma in rats. Laser Med Sci 2014;29(3): 1043-450. https://doi.org/10.1007/s10103-013-1456-5.

[60] Budaev BB. The use of helium-neon laser in the complex therapy of bronchial asthma. Abstract of the thesis. Moscow. 1990 [Russian].

[61] Borzenkov SA. Effect of low-power helium-neon laser therapy on the rheological properties of blood in patients with bronchial asthma. Abstract of the thesis. Moscow. 2000 [Russian].

[62] Karpukhina EP. Treatment of bronchial asthma using laser therapy and enterosorption. Abstract of the thesis. Moscow. 1994 [Russian].

[63] Goldina EM. Comparative evaluation of the clinical efficacy of various low-intensity laser irradiation methods in the complex treatment of patients with bronchial asthma. Abstract of the thesis. Ryazan. 2004 [Russian].

[64] Makarova VG, Goldina EM. Low-intensive laser emanation influence on adrenomimetics and glucocorticosteroids dose in complex therapy of bronchial asthma. I.P. Pavlov Russ Med Biol Herald 2004;3-4:30-5 [Russian].

[65] Dimov AS, Sobolev VA, Merkusheva IA, Glukhikh NV. The effectiveness of laser irradiation of blood in combination with drug therapy for bronchopulmonary diseases. Abstracts of the scientific-practical conf. "Methods of efferent and quantum therapy in clinical practice."- Izhevsk. 1995. p. 225-6 [Russian].

[66] Runkelova IV. The use of intravenous laser therapy in the complex treatment of patients with bronchial asthma. Abstract of the thesis. Leningrad. 1989 [Russian].

[67] Fedorova OF. The state of hemostasis, hemorheology, microcirculation and central hemodynamics in patients with bronchial asthma on the background of drug and laser therapy. Abstract of the thesis. Saratov. 2000 [Russian].

[68] Kravets ES. Morphofunctional state of endobronchial microhemocirculation in patients with bronchial asthma during treatment with glucocorticoids. Thesis. Blagoveshchensk. 2006 [Russian].

[69] Prikhodchenko AA. The reaction of the human immune system to extreme factors as an indicator of the adaptability of the organism. Abstract of the thesis. Novosibirsk. 1989 [Russian].

[70] Kolodeznaya IL. Oxidant and antioxidant systems in patients with bronchial asthma depending on the methods of using glucocorticosteroids in treatment, correction of disorders. Abstract of the thesis. Barnaul. 2004 [Russian].

[71] Farkhutdinov UR. Intravascular laser irradiation of blood in the treatment of patients with bronchial asthma. Terapevticheskiy arkhiv 2007;79(3):44-8 [Russian].

[72] Rakita DR. Free radical status in the clinic of internal diseases and the possibility of its correction. Abstract of the thesis. Ryazan. 1999 [Russian].
[73] Rakita DR, Lunyakov VA, Uryasiev OM, Garmash VY. Free radical status at the patients with asthma and opportunity of its correction. I.P. Pavlov Russ Med Biol Herald 2000;1-2: 77-85 [Russian].

[74] Rakita DR, Uryasiev OM, VYa Garmash, Ivanova MV, Krasnovid NI, Lebedev AV. Effect of laser therapy on lipids and antioxidants in the blood of patients with bronchial asthma. Terapevticheskiy arkhiv 1997;12:49-50 [Russian].

[75] Korzhov VI, Dzublik AY, Sokirko TA. Intravascular laser therapy in the complex treatment of patients with bronchial asthma. Abstracts of the All-Union. conf. "Effect of lowenergy laser irradiation on blood». Kiev. 1989. p. 104-6 [Russian].

[76] Uryasiev OM. The effect of laser therapy on the content of lipoperoxides and lipid-soluble antioxidants in the blood of patients with bronchial asthma. Abstract of the thesis. Ryazan. 1999 [Russian].

[77] Isaeva IA. Efficiency of various combinations of physical factors in the complex therapy of bronchial asthma with concomitant hypertensive disease. Abstract of the thesis. Ryazan. 2018 [Russian].

[78] Uryasev OM, Isaeva IA. Intravenous laser therapy and interval normobaric hypoxytherapy effectiveness in asthma and comorbid essential hypertension complex therapy. I.P. Pavlov Russ Med Biol Herald 2014;2:113-7. https://doi.org/ 10.17816/pavlovj20142111-115 [Russian].

[79] Uryasev OM, Isaeva IA. Intravenous lasertherapy and interval normobaric hypoxytherapy effectiveness in asthma and comorbid essential hypertension complex therapy. Zemskiy vrach 2014;1:3-4 (24): 25-28. [Russian].

[80] Papkov SV. Comparative evaluation of the effectiveness and selection of the individual dose during percutaneous and intravenous laser therapy in patients with bronchial asthma. Abstract of the thesis. - Ryazan. 2002 [Russian].

[81] Borisova TV. Changes in cytokine profile, cellular and humoral immunity and their correction in bronchial asthma. Abstract of the thesis. - Moscow. 2017 [Russian].

[82] Zarembo IA. Clinical-instrumental, immunological and cytochemical criteria for the effectiveness of laser therapy in patients with non-specific lung diseases. Abstract of the thesis. - Saint Petersburg. 1989 [Russian].

[83] BYa Bart, Soloviev SS, Golovko MG. Successful use of intravenous laser therapy in polyclinic practice for the prevention of recurrence of bronchial asthma. In: Proceedings of the VII National congress on respiratory diseases. Moscow; 1997. 0575. [Russian].

[84] Toygabaev AA, Lapin VI, EZh Amralin. The use of lowenergy laser in patients with emergency conditions. Abstracts of the All-Union. conf. "Effect of low-energy laser irradiation on the blood." Kiev. 1989. p. 163-5 [Russian].

[85] DKh Dautov. Clinical and immunological parameters of laser-activated blood in patients with chronic obstructive bronchitis and bronchial asthma. Abstract of the thesis. Karaganda. 1996 [Russian].

[86] Solovyov SS. The use of helium-neon laser in outpatient practice in patients with bronchial asthma for the purpose of treatment and secondary prevention. Abstract of the thesis. Moscow. 1996 [Russian].

[87] Vasilyeva LV. Clinical and genetic prediction of the effectiveness of various types of laser therapy in patients with bronchial asthma. Abstract of the thesis. Voronezh. 1999 [Russian].

[88] Proskuryakov VV. Lipid peroxidation and hemostasis, ways to correct their disorders in patients with bronchial asthma. Abstract of the thesis. Perm. 1995 [Russian].

[89] Sarycheva TG, Tsybzhitova EB, Popova OV, Aleksandrov OV. The morphometry and electrophoretic mobility of red blood cells from patients with asthma in the intravenous laser irradiation treatment of blood. Klin Lab Diagn 2009;3:13-4 [Russian].

[90] Vinogradov DL. Laser therapy and plasmapheresis in the treatment of patients with bronchial asthma. Abstract of the thesis. Moscow. 1995 [Russian]. 
[91] Maslova LV. The use of hemosorption and intravenous laser irradiation of blood in the complex treatment of patients with aspirin asthma. Abstract of the thesis. Minsk. 1996 [Russian].

[92] Kozlovsky SO. Method of treating bronchial asthma. Patent 77108 UA, 06.08.2012.

[93] Khadartsev AA, Danilyak IG, Khoruzhaya VA. Laser autohemotransfusion in the treatment of bronchial asthma. In: New methods of diagnosis and rehabilitation of patients with nonspecific lung diseases, vol. 2. Moscow-Barnaul; 1985. p. 141-2 [Russian].

[94] Sveklo LS. Methods of extracorporeal effects on the blood in the treatment of emergency conditions. Abstract of the thesis. Voronezh. 1997 [Russian].

[95] Gusinskaya VV. Analysis of UV-induced structural and functional changes in proteins of the complement system and erythrocyte membranes. Abstract of the thesis. Voronezh. 1995 [Russian].

[96] Ishina TI. Efficiency of using intravenous laser blood irradiation, plasmapheresis and their combined use in the complex treatment of patients with bronchial asthma. Abstract of the thesis. Moscow. 1998 [Russian].

[97] Ishina TI, Kakhnovsky IM, Makarova OV. Study of the clinical efficacy of intravenous laser blood irradiation, plasmapheresis, and their combination in patients with bronchial asthma. Terapevticheskiy arkhiv 2001;73(3):15-9 [Russian].

[98] Kildyushevskiy AV. Extracorporeal hemocorrection for lympho-proliferative and autoimmune diseases. Abstract of the thesis. Moscow. 1997 [Russian].

[99] Kuno AS. Cascade extracorporal blood treatment in the treatment of bronchial asthma. Abstract of the thesis. Voronezh. 1994 [Russian].

[100] Ermukhambetov TK, Kuchin NN. About some functional indicators of respiration in patients with bronchial asthma during treatment with laser irradiation. Some issues of biodynamics and bio-energy of the body under normal and pathological conditions, biostimulation with laser irradiation. Part 2. Alma-Ata. 1972. p. 137-41 [Russian].

[101] Staroverov AT, Aleksandrovich LM. The effect of laser exposure on biologically active points in bronchial asthma. Abstracts of the All-Union. conf. on applic. of lasers in medicine (Krasnoyarsk, 1983). Moscow. 1984. p. 124-5 [Russian].

[102] Khadartsev AA, Danilyak IG, Khoruzhaya VA. Laserpuncture in bronchial asthma. Scientific and technological progress and health care. Tula; 1987. p. 134-5 [Russian].

[103] Balgabekova AK. Combined method of treatment of associated bronchial asthma: specific desensitization and laser therapy. Abstract of the thesis. Almaty. 1995 [Russian].

[104] Borodina MA. The effectiveness of the method of multicomponent physiotherapy effect on biologically active points in bronchial asthma. Abstract of the thesis. Tomsk. 1999 [Russian].

[105] Esaulenko IE, Nikitin AV, Shatalova OL. The use of laseropuncture in patients with bronchial asthma and concomitant chronic rhinosinusitis. Vopr Kurortol Fizioter Lech Fiz Kult 2009;1:37-9 [Russian].

[106] Ayylchiev AE. The effectiveness of laser therapy in the complex treatment of bronchial asthma in children. Abstract of the thesis. Bishkek. 1995 [Russian].

[107] Aytmukhanova LM, Abylgazinova AA. On some indicators of peripheral blood in patients with bronchial asthma during treatment with laser irradiation. Some issues of biodynamics and bio-energy of the body under normal and pathological conditions, biostimulation with laser irradiation. Part 2. Alma-Ata. 1972. p. 147-50 [Russian].

[108] Gilmetdinov RR, Glotov AV, Davletkildeev NA, Lobov IA, Trushnikov GS. Change in the morphofunctional state of the lymphocyte membranes of patients with bronchial asthma induced by $\mathrm{He}-\mathrm{Ne}$ laser radiation. Herald Omsk Univ 2013;vol. 2(68):133-6 [Russian].

[109] Nikitin AV, Titova LA. Clinical efficacy of targeted low-intensity laser irradiation on the projection of adrenal glands in patients with bronchial asthma. Terapevticheskiy arkhiv 2006;78(3):39-40 [Russian].

[110] Titova LA, Nikitin AV. Comparative evaluation of local and systemic low-intensive laser irradiation clinical efficiency in the treatment of patients with bronchial asthma on the background of hormonal disorders. J N Med Technol 2009; 16(4):217-9 [Russian].

[111] Palagutin AG. Some indicators of mineral metabolism in patients with bronchial asthma during treatment with laser irradiation. Some issues of biodynamics and bio-energy of the body under normal and pathological conditions, biostimulation with laser irradiation. Part 2. Alma-Ata. 1972. p. 145-7 [Russian].

[112] Bekturganova ZR. On the state of coagulation and anticoagulation systems of blood in patients with bronchial asthma during treatment with laser energy. Some issues of biodynamics and bio-energy of the body under normal and pathological conditions, biostimulation with laser irradiation. Part 2. Alma-Ata. 1972. p. 143-5 [Russian].

[113] Nikitin AV, Chernaya LS. Laser therapy in treating metabolic syndrome at patients with bronchial asthma. J N Med Technol 2011;18(2):308-10 [Russian].

[114] Nikitin AV, Chernaya LS, Tlhova JS. The complex medicamental and non-medicamental correction in patients with bronchial asthma in combination with metabolic syndrome. J N Med Technol 2011;18(3):54-5 [Russian].

[115] Chernaya LS. Complex correction of metabolic syndrome using low-intensity laser irradiation in patients with bronchial asthma. Abstract of the thesis. Voronezh. 2013 [Russian].

[116] Saenko LV. The level of peripheral blood proteins and lipids in patients with bronchial asthma during treatment with laser irradiation. Some issues of biodynamics and bioenergy of the body under normal and pathological conditions, biostimulation with laser irradiation. Part 2. AlmaAta; 1972. p. 141-3 [Russian].

[117] Kucheryavyy AM. Magnetic laser therapy in patients with bronchial asthma in combination with hypertension. Abstract of the thesis. Saint Petersburg. 2007 [Russian].

[118] Moskalenko IT. The effect of low-intensity laser irradiation on the indices of endogenous intoxication and inflammatory activity of the bronchial mucosa in patients with bronchial asthma. Abstract of the thesis. Voronezh. 2007 [Russian].

[119] Tolstykh EM. The use of mildronate and low-intensity laser irradiation in the complex therapy of bronchial asthma. Abstract of the thesis. Voronezh. 2008 [Russian].

[120] Tolstykh EM, Karpukhina EP, Vasilyeva LV. Clinic effectiveness of metabolic therapy and supravenous laser radiation of blood in the patients with bronchial asthma and arterial hypertension. J N Med Technol 2013;20(2):187-91 [Russian].

[121] Treschalina YuB. The use of combined laser therapy in patients with bronchial asthma with concomitant chronic rhinosinusitis. Abstract of the thesis. Voronezh. 2004 [Russian].

[122] Melnikova AA, Basiev OZ. Laser technologies in the treatment of patients with bronchial asthma. On-line Sci Educ Bull "Health Educ Millenn" 2006;8(11):506 [Russian].

[123] Titova LA. Clinical and experimental substantiation of the effectiveness of the use of combined laser therapy in patients with bronchial asthma. Abstract of the thesis. Voronezh. 2006 [Russian].

[124] Vasilyeva LV, Tikhova YuS, Titova LA, Izmalkov DV. The clinical efficacy of laser therapy in the treatment and prevention of osteoporosis in patients with bronchial asthma on the background of hormonal disorders. In: Proceedings of XXXIV Internat. scientific and practical conf. "The use of lasers in medicine and biology. Sudak; 2010. p. 60-2 [Russian].

[125] Nikitin AV, Titova LA. The method of combined treatment of bronchial asthma. Patent 2420331 RU, 09.12.2009. [Russian]. 
[126] Belov AA, Tsvetkova OA, Rapoport SI, Rasulov MI. Method of treatment of bronchial asthma. Patent 2114653 RU, 28.06.94. [Russian].

[127] Kryuchkova AV, Chernaya LS, Lebedeva AV. Low-intensity laser irradiation and chromotherapy in the treatment of patients with bronchial asthma with metabolic syndrome. In: Proceedings of XXXV Internat. scientific and practical conf. "The use of lasers in medicine and biology. Kharkov; 2011. p. 57 [Russian].

[128] Moskvin SV. Only lasers can be used for low level laser therapy. Biomedicine 2017;7(4):4-11. https://doi.org/ $10.1051 / \mathrm{bmdcn} / 2017070422$.

[129] Благовещенск-на-AMype Avdeeva NV. Comparative effectiveness of various methods of pathogenetic therapy in patients with bronchial asthma. abstract of the thesis. Blagoveshchensk-on-Amur; 1997 [Russian].

[130] Sadigov AS. Bronchial asthma in patients with respiratory tuberculosis. Abstract of the thesis. Saint Petersburg. 2004 [Russian].
[131] Bashkatova VN, Khadartsev AA, Morgunova IN, Lukashin BA. Plasmapheresis (PA), laser irradiation (LI) electromagnetic radiation of the millimeter range (EMR $\mathrm{mm}$ ) in patients with bronchial asthma. Abstracts to the 125th anniversary of the opening of the Tula regional hospital. Tula. 1992. p. 45-6 [Russian].

[132] Grosheva ES. Efficiency of combined use of EHF-puncture and low-intensity laser therapy in the complex treatment of patients with bronchial asthma. Abstract of the thesis. Voronezh. 2009 [Russian].

[133] Grosheva ES, Kondusova YV, Poletaeva IA. Remote results of extremely high frequency laser therapy at patients with bronchial asthma. J N Med Technol 2011;18(2):246-8 [Russian].

[134] Yusupalieva MM, Savtchenko VM. The effectiveness of combined laser therapy for the treatment of the patients presenting with bronchial asthma and concomitant allergic rhinitis. Vopr Kurortol Fizioter Lech Fiz Kult 2017;94(4):14-8. https://doi.org/10.17116/kurort201794414-18 [Russian]. 